\title{
Analysis of the Space and Time Distribution of Syphilis in Brazil: Cases of Acquired Syphilis From 2010-2018 and Congenital and Syphilis in Pregnant Women From 2001-2017
}

\section{Ângelo Antônio Oliveira Silva}

Goncalo Moniz Institute

Leonardo Maia Leony

Goncalo Moniz Institute

Wayner Vieira de Souza

Aggeu Magalhaes Institute

Natália Erdens Maron de Freitas

Goncalo Moniz Institute

Ramona Tavares Daltro

Goncalo Moniz Institute

Emily Ferreira dos Santos

Goncalo Moniz Institute

Larissa de Carvalho Medrado Vasconcelos

Goncalo Moniz Institute

Maria Fernanda Rios Grassi

Goncalo Moniz Institute

Carlos Gustavo Regis-Silva

Goncalo Moniz Institute

Fred Luciano Neves Santos ( $\nabla$ fred.santos@fiocruz.br )

Gonçalo Moniz Institute https://orcid.org/0000-0002-3944-0818

\section{Research Article}

Keywords: Acquired syphilis, Congenital syphilis, Syphilis in pregnant women, time distribution, Annual Percentage Change, Notification

Posted Date: November 17th, 2020

DOl: https://doi.org/10.21203/rs.3.rs-105722/v1 
License: (c) (i) This work is licensed under a Creative Commons Attribution 4.0 International License. Read Full License 


\section{Abstract}

Background. In Brazil, the notification of acquired syphilis (AS), congenital syphilis (CS) and syphilis in pregnant women $(\mathrm{SiP})$ is compulsory. Notification data provided by the Ministry of Health $(\mathrm{MoH})$ in combination with the mapping of vulnerable geographic areas is essential to forecasting possible outbreaks and more effectively combating infection through monitoring. We aim evaluated the space and time distribution of reported cases of CS and SiP in Brazil (2001 to 2017), as well as an estimation of cases of AS (2010 to 2018).

Methods. A retrospective ecological study was carried out using secondary surveillance data obtained from the Brazilian National Notifiable Diseases Information System (SINAN) database, considering all reported cases of CS and SiP between 2002 to 2017, as well as MoH epidemiological bulletin data regarding cases of AS between 2010 to 2018. Epidemiological characteristics and time trends were analyzed using joinpoint regression models and spatial distribution (three-year moving averages), considering microregions or states/macroregions as units of analysis.

Results. A total of $188,630(5.4 / 100,000)$ CS, $235,895 \operatorname{SiP}(6.3 / 100,000)$ and 479,731 cases of AS $(27.4 / 100,000)$ were reported during the periods studied. The epidemiological profile of Brazil indicates most reported CS cases occurred among 'mixed-race' newborns who were diagnosed within seven days after birth and whose mothers had received prenatal care. Regarding SiP, most cases were among women who self-reported 'mixed-race', were aged 20-39 years, had up to eight years of formal education and were diagnosed with primary or latent syphilis. Overall, rates of AS rose around 400\% from 2010 to 2018 . Nearly all microregions reported at least one case of CS and SiP. From 2012 to 2016, CS cases increased significantly in almost all Brazilian states, most notably in the South, Southeast, and Central-West macroregions, from 2001-2018 and the relative risk of SiP increased around 4,000\%.

Conclusions. Considering the epidemiological scenario of the infection in Brazil, it is necessary to enhance preventive, control and eradication measures.

\section{Background}

Syphilis, a sexually transmitted infection (STI), is a persistent public health issue. Increasing confirmed cases has been reported since 1990 among all age groups and a variety of ethnicities [1]. In 2015, almost 18 million cases of acquired syphilis (AS) were reported among men and women aged 15 to 49 years worldwide [2]. Around one million pregnant women become infected each year, resulting in approximately 300,000 fetal and neonatal deaths, placing more than 200,000 children at risk of premature death. In Brazil, 119,800 cases of AS, 49,013 cases of syphilis in pregnant women (SiP) and 24,666 cases of congenital syphilis (CS) were notified in 2017 [3].

Syphilis, a systemic infection exclusive to humans caused by the bacterium Treponema pallidum subsp. pallidum [4], is mainly transmitted through unprotected sexual activity (acquired syphilis) [5]. Less commonly, non-sexual transmission can occur through treponemal lesions or by exposure to blood or 
contaminated body fluids [6-8]. In vertical transmission from mother-to-child (CS), following direct contact with the bacterium by the mother, infection spreads to the fetus hematologically, predominantly via the transplacental route [9]. Most of the signs and symptoms of the disease, e.g. tissue damage, arise from the inflammatory reaction to infection [10].

Despite the existence of diagnostic tests and effective antibiotic treatment, increasing numbers of syphilis cases registered in Brazil reflect the fragility of the public health system. In accordance with Brazilian Health Regulations (Ordinances 542 for CS - 1986, 33 for SiP - 2005, and 2,472 for AS - 2010), confirmed syphilis infection requires compulsory notification to contribute to incidence/epidemiological investigations. The notifications sent to public health authorities provide data to the Ministry of Health for monitoring and to predict potential outbreaks [11]. Although national estimates facilitate international comparisons, these cannot solve heterogeneity at the geographical level where public health actions usually take place. Using finer scales to monitor disease variation and to identify high-risk communities is a critical aspect to develop targeted interventions towards the reduction of the burden of communicable diseases [12].

Globally, rising numbers of syphilis cases have also been reported in the United States, Canada, Europe, Russia and China, which has drawn attention to a public health crisis linked to the synergy between the epidemiology and biology of syphilis and the human immunodeficiency virus [13]. In Latin America, Asia and Africa, recent increases in case frequency and the size of affected geographic areas have marked a new era of infection transmission, seriously burdening limited-resource public health systems [14]. Studies on the incidence of infectious disease in terms of spatial distribution have proven important for public health analysis, especially with respect to the planning and execution of measures aimed at controlling disease. The present study evaluated the space and time distribution of reported cases of congenital and syphilis infection in pregnancy in Brazil between the years of 2001 and 2017, as well as an estimation of acquired syphilis between 2010 and 2018.

\section{Methods}

\section{Ethical statements}

As this study was based on secondary data, and all presented information is in the public domain, none of the described variables allowed for individual identification. In 2016, a new resolution published by the Brazilian National Health Council abrogated the need to seek approval from any Institutional Review Board for studies using publicly available secondary data that does not provide individually identifiable information (http://conselho.saude.gov.br/resolucoes/2016/reso510.pdf).

\section{Study area}

This study was performed in Brazil, the fifth largest country in the world, with a total area of 8,515,767 $\mathrm{km}^{2}$. The Federative Republic of Brazil is comprised of 26 states and a Federal District, which were grouped into five macroregions (Central-West, North, Northeast, South, and Southeast-see Fig. 1), 137 
mesoregions and 558 microregions by the Brazilian Institute of Geography and Statistics (IBGE) according to economic and social similarities. According to the 2015 Brazilian national census, the country's total population size was $204,338,473$ inhabitants, with an overall density of 24 inhabitants per $\mathrm{km}^{2}$ (data available at http://www.ibge.gov.br).

\section{Study design}

A retrospective ecological study was carried out using data from the open-access Brazilian National Notifiable Diseases Information System (SINAN) database, considering all reported cases of CS and SiP between 2001 to 2017 (data available at http://datasus.saude.gov.br). All cases reported by the 5,567 Brazilian municipalities were included in this study, and then grouped in the 558 microregions established by IBGE. Other variables were also analyzed in this study according to the classification of syphilis notification. With respect to SiP, race/ethnicity, age group, clinical stages of syphilis and years of study were considered. For CS, the variables of sex, race/ethnicity, age group and presence/absence of prenatal care were analyzed. Since cases of AS are not included in the SINAN compulsory notification scheme, data available from the epidemiological bulletin published by the Brazilian Ministry of Health (2018) were analyzed according to state and macroregion from 2010 to 2018 [11].

\section{Statistical analysis}

The distribution of cases of AS, CS and SiP were evaluated using spatial analysis methods and geoprocessing techniques. Data on CS and SiP were analyzed according to the microregion in which notification occurred to allow for greater precision in intra- and inter-regional differences, and also to aid in revealing specific areas in which to target potential intervention efforts. Cases of AS were analyzed on a state and macroregion level. To minimize potential interference from random fluctuations that could occur in time-series studies, distribution maps were constructed using three-year moving averages from 2001 to 2017 for CS and SiP, and between 2010 and 2018 for AS cases; annual notification rates was calculated for 558 Brazilian microregions and five macroregions and 26 states plus the Federal District, respectively. The infection rate, expressed as the number of infected individuals per 100,000 inhabitants, was used to constructed thematic maps. Trends changes in annual notification rates were calculated using the joinpoint regression model and expressed as Annual Percentage Change (APC) with 5\% significance $(p<0.05)$. Digital maps were obtained from the IBGE cartographic database in shapefile (.shp) format, then reformatted and analyzed using QGIS version 3.10 (Geographic 140 Information System, Open Source Geospatial Foundation Project. http://qgis.osgeo.org). This software package was used for data processing, analysis and the presentation of cartographic data. A checklist (see Additional file 1) is provided according to the Strengthening the Reporting of Observational studies in Epidemiology (STROBE) guidelines.

\section{Results}

Annual Percentage Change (APC) in syphilis cases 
Between 2001 and 2017, 188,630 cases of CS and 235,895 cases of SiP were reported in Brazil. The mean overall rate of CS was 5.4 cases per 100,000 inhabitants during the period studied, ranging from 2.5 to 12.4 , while the mean rate per 100,000 inhabitants of SiP was 6.3, ranging from 0.02 to 19.1. In regard to AS, 479,731 cases were estimated between 2010 and 2018, with a mean annual rate of 27.4 cases per 100,000 inhabitants (range: 8.6 to 45.3). From 2002 to 2016, joinpoint regression analysis revealed a generally increasing trend (Fig. 2), highlighting three distinct and statistically significant epidemiological periods. With respect to CS (Fig. 2A), an average annual notification rate of 2.9 cases per 100,000 inhabitants was seen in the first period (2002 to 2009; APC $=10.31$ [95\% Cl: 0.5, 5.2], Z = 2.9, $p<$ 0.05), which increased to 6.2 in the second period (2009 to 2014; APC $=25.47$ [95\% Cl: $19.9 ; 31.3], Z=$ $11.8, p<0.05)$. Finally, in the third period (2014 to 2016), the number of cases rose to 11.1 per 100,000 inhabitants (APC $=11.44$ [95\% Cl: 1.3; 22.6], $Z=2.7, p<0.05$ ). Considering SiP (Fig. 2B), an average annual notification rate of 0.6 cases per 100,000 inhabitants was observed in the first period (2002 to 2006; APC $=203.26$ [95\%Cl: 81.4; 406.9], $Z=5.1, p<0.05$ ), which increased to 6.6 per 100,000 inhabitants (2006 to 2014; APC $=27.50$ [95\%Cl: 23.8; 31.3], $Z=19.4, p<0.05$ ) in the second period. In the third period, the number of cases increased dramatically to 16.6 cases per 100,000 inhabitants (APC $=16.47$ [95\% Cl: $3.6 ; 30.9], Z=3.6, p<0.05$ ). Periods 1 and 2 of the three epidemiological periods identified by joinpoint regression in both CS and SiP were not similar in terms of length or specific years; however, Period 3 was coincident between these two infections. In spite of an increasing APC trend seen in AS during the period analyzed (2011-2017), no statistical significance was detected regarding this form of infection (data not shown).

\section{Sociodemographic profile of syphilis in Brazil}

Fig. 3 (see Additional file 2) illustrates changes in the profiles of the sociodemographic variables of CS cases during the three periods identified. Considering racial classification, the North, Northeast and Central-West macroregions reported more cases of CS among children who were identified as 'mixed-race' in the three periods: P1 (64.3\%), P2 (78.6\%), P3 (82.2\%); P1 (51.2\%), P2 (67.3\%), P3 (70\%) and P1 (29.6\%), P2 (44.9\%), P3 (51\%), respectively. In the Southeast macroregion, more CS cases (25.9\%) were identified among children identified as 'white' in P1, while in P2 (35.1\%) and P3 (40.2\%) more cases were identified as 'mixed-race'. Conversely, in the South macroregion, CS was predominant among children identified as 'white' in P1 (59.7\%), P2 (66.4\%) and P3 (66.7\%). With respect to age, more than $88 \%$ of the reported cases were diagnosed among children less than 7 days old in all periods and all macroregions. With respect to prenatal care among the CS cases, over $70 \%$ reported receiving prenatal care regardless of period and macroregion, suggesting a lack of protection against CS. Interestingly, CS was generally reported in all macroregions at similar frequencies among males and females (about 50\%).

Fig. 4 (see Additional file 3) illustrates changes in the sociodemographic profile of SiP during the three distinct periods identified. With respect to self-reported skin color, the North and Northeast macroregions reported more cases of SiP in women who self-identified as 'mixed-race' throughout all periods: from $64.7 \%$ and $64.5 \%$ in P1, to $80.5 \%$ and $66.6 \%$ in P3, respectively. Among women who self-identified as 'white', most cases were concentrated in the South (49.7\%) and Southeast (43.7\%) macroregions in P1, 
while $67.1 \%$ of cases were reported in the South macroregion in P3. With respect to age, more than $66 \%$ of cases were reported in women aged 20 to 39 years in all macroregions and all three periods. Regarding education level, most reported cases were concentrated in pregnant women who had up to eight years of formal schooling in all three periods. With respect to clinical stage of syphilis, in P2 most pregnant women had primary syphilis (over $40 \%$ in all macroregions), while in P3 primary syphilis was predominant in the North (47.6\%), Northeast (34.5\%), South (35.2\%) and Central-West (29\%). Most cases of latent syphilis were concentrated in the Southeast (34.1\%) in P3. No data was available in the SINAN database during period 1.

\section{Space and time distribution analysis}

Fig. 5 (see Additional file 4) illustrates the space and time distribution of reported AS cases over time, with significant changes seen in the notification rates of AS throughout Brazil in seven distinct time points by state. Initially, in 2011, relatively low numbers of AS cases ( $<16$ cases per 100,000 inhabitants) were seen in almost all states, with the exception of Mato Grosso do Sul, São Paulo and Espírito Santo. By 2013, higher notification rates were concentrated in the states of Rio Grande do Sul, São Paulo and Espírito Santo (49-64 cases/100,000 inhabitants). By 2017, AS was much more widely distributed throughout the country, with notably significant increases seen in Rio Grande do Sul and Santa Catarina (>80 cases per 100,000 inhabitants), Mato Grosso do Sul (65-80 cases per 100,000 inhabitants), Paraná, São Paulo and Tocantins (49-64 cases per 100,000 inhabitants), as well as Minas Gerais, Rio de Janeiro, Sergipe, the Federal District and Roraima (33-48 cases per 100,000 inhabitants). Overall, the rate of AS rose around 400\% from 2010 to 2018 in Brazil, with the most significant increases seen in Santa Catarina (+1010\%), Rio Grande do Sul (+930\%), Mato Grosso do Sul (+602\%), as well as Tocantins, Paraná and Espírito Santo $(+>500 \%)$ states.

Fig. 6 (see Additional file 5) depicts the space and time distribution of reported numbers of CS cases at 15 distinct time points. Overall, significant changes in the notification rates throughout Brazil are evidenced over time. Between 2002 and 2016, infection rates increased significantly from 2.5 to 12.4 per 100,000 inhabitants/year. The number of positive cases was found to increase in some microregions in Amapá, Espírito Santo, Tocantins, Pernambuco and Maranhão states, especially until 2007. The high numbers of cases were reported in the microregions of Macapá-AP (17.0 cases per 100,000 inhabitants), Linhares-ES (15.2 cases per 100,000 inhabitants) and Araguiana-TO (18.0 cases per 100,000 inhabitants). Interestingly, until 2012, increasing numbers of cases were notified in Continguiba-SE (29.3 cases per 100,000 inhabitants), Aracaju-SE (29.2 cases per 100,000 inhabitants) and Estância-SE (15.3 cases per 100,000 inhabitants). From 2012 to 2016, the cases of CS achieved a significant increase in almost all states, highlighting the South, Southeast, and Central-West macroregions.

The space and time distribution of reported rates of $\mathrm{SiP}$ is showed at 15 distinct time points in Fig. 7 (see Additional file 6). SiP rates were low in the country, in 2002 and 2003 years. Between 2002 and 2016, infection rates increased significantly from 0.04 to 19.1 per 100,000 inhabitants/year. In the North macroregion, Japurá-AM microregion shown high- notification rate from 2005 to 2016 reaching a peak of 
5,122 cases per 1000,000 inhabitants in 2016. The Cassilândia-MS microregion also presented an increased in the numbers reaching 671 cases per 1000,000 inhabitants in 2016. On the other hand, from 2012 the number of positive cases was found to increase in some microregions of at least 13 states, as Santo Antônio de Pádua-RJ (1,994 cases per 1000,000 inhabitants in 2016), Itaguara-MG (1,278 cases per 1000,000 inhabitants in 2016), Jeremoabo-BA (791 cases per 1000,000 inhabitants in 2016) and Ibaiti-PR (683 cases per 1000,000 inhabitants in 2016). From 2001 to 2018 the relative risk of SiP increased about $4,000 \%$ in the country, highlighting only 556 microregions, except Oiapoque-AP and Brasília-DF which presented zero rates.

\section{Spatial distribution of syphilis cases}

Fig. 8 (see Additional file 7) illustrates the total number of cumulative cases of syphilis at the end of the evaluated periods, with states or microregions used as units of analysis. Between 2010 and 2018, most of the country experienced increased numbers of AS cases. By 2018, the highest rates of AS were found in the geographic south of the country (Rio Grande do Sul: 481, Espírito Santo: 459, and Mato Grosso do Sul: 424) versus 39 in Piauí and 37 in Alagoas states, both located in the geographic north. Of the 558 microregions evaluated between 2001 and 2017, 549 (98.4\%) and 558 (100\%) reported at least one case of CS and SiP, respectively. The spatial distribution of CS indicated that the Rio de Janeiro-RJ microregion had the highest cumulative notification rate $(544 / 100,000)$. High numbers of cases were also reported in other microregions: Aracaju-SE $(384 / 100,000)$, Cotinguiba-SE $(366 / 100,000)$ and Araguaína-TO $(359 / 100,000)$. With regard to SiP, higher notification rates were observed in the Japurá-AM $(23,877 / 100,000)$, Santo Antônio de Pádua-RJ $(14,603.7 / 100,000)$ and Itaguara-MG $(6,441 / 100,000)$ microregions.

\section{Discussion}

We performed a systematic space and time distribution analysis of reported cases of AS, CS and SiP in Brazil, and also described the distribution of infection throughout the country during the respectively studied periods. Overall, our results indicate the existence of a distinct trend for each form of syphilis, with an increasing tendency in case numbers over time. In fact, data reveal the number of cases has been growing in recent years, suggesting that syphilis remains a public health concern in the country. The high number of cases of CS and SiP observed from 2011 to 2017 could have been due to the implementation of a governmental program in 2011 called "Rede Cegonha", which expanded early detection efforts as a result of periodic screening for prenatal, intrapartum and postpartum syphilis. Moreover, between 2012 and 2015, the Brazilian Ministry of Health's Department of Surveillance, Prevention, and Control of STI, AIDS and Viral Hepatitis quintupled the distribution of rapid tests for syphilis throughout the country's Unified Health System (SUS) $[15,16]$.

Between 2010 and 2018, 479,731 notifications for AS were reported (27.4 cases/100,000 inhabitants), followed by $235,895 \mathrm{SiP}$ notifications $(6.33$ cases $/ 100,000)$ and 188,630 notifications for CS $(5.38$ cases/100,000) between 2001 and 2017. These figures are consistent with analyses published by the 
Ministry of Health, which indicate an increase from 1.7 to 8.6 cases/1,000 live births for CS between 2003 and 2017. Additionally, the detection rate in pregnant women rose from 0.5 to 17.2 cases per 1,000 live births between 2005 and 2017, while the detection rate of AS jumped from 2.0 to 58.1 cases per 100,000 inhabitants from 2010 to 2017 [17]. According to a systematic review study evaluating the prevalence of SiP and CS in Brazil from 2002-2017, the prevalence of infection throughout the country remained above the 2016 target established by the World Health Organization (WHO) [18]. The strategy to combat sexually transmitted infections (STIs) from 2016 to 2021 prioritizes the elimination of congenital syphilis by implementing comprehensive syphilis screening and treatment among pregnant women, as well as in specific populations, with a goal of reducing the global incidence of syphilis by $90 \%$, with 50 or fewer cases of CS per 100,000 live births in $80 \%$ of the countries worldwide by 2030 [19]. Furthermore, in comparison to data published in international studies, the notification rates of CS are significantly higher in Brazil than those reported in other countries [18]. It is important to note that changes in the epidemiologic infection profile in recent years are likely associated with: a) increased testing coverage enabled by the adoption of rapid diagnostic tests, which therefore allowed for the expanded identification of incident cases throughout the country, and b) the shortage of benzathine penicillin, which, since 2014, has affected Brazil, as well as other countries, due to a deficit of raw materials required for its production. Consequently, this shortage contributed to increases in untreated or inadequately treated syphilis in pregnancy, which directly led to higher rates of CS $[20,21]$. On the other hand, surveillance data also show that the general profiles of those infected contain reports of high numbers of sexual partners, unprotected sex, recreational drug use and the use of sex-oriented social networking apps [17].

The present study also investigated the epidemiological profile of syphilis in both maternal and newborn populations in Brazil. A similar prevalence ( 50\%) was observed between both male and female cases of CS, which stands in accordance with a study conducted in the south of Brazil, which found no significant differences in notification rate according to sex. This can be explained by the fact that CS is transmitted vertically and that infection transmissibility is influenced by the mother's infection stage and fetal exposure [22]. With respect to race/ethnicity, the majority of reported CS cases occurred among newborns identified by the family as 'mixed-race'. Other data have also shown that the notification rate of congenital syphilis tends to be significantly higher in black or 'mixed-race' children. In fact, several studies have linked cases of CS with family history, including the racial classification of children's parents, with high numbers of pregnant women self-identifying as 'mixed-race' or black [22-25].

Herein, most cases of CS were diagnosed less than seven days after birth, and most mothers reported receiving prenatal care. It has been reported that CS diagnosis usually occurs within seven days after birth (typically between the $1^{\text {st }}$ and $2^{\text {nd }}$ day of life) $[23,25]$. In addition to prematurity, newborns usually present classic signs and symptoms of infection soon after birth, including low birth weight, anemia, jaundice, respiratory distress, visceromegaly, congenital malformations, serosanguinous discharge and rhinitis, skin lesions, heart disease and/or hearing loss [23,26,27]. Interestingly, it was found that despite the predominance of prenatal care in $70+\%$ of the CS cases investigated herein, significantly high numbers of cases of CS were nonetheless reported throughout the country. While prenatal care is 
becoming more commonplace in Brazil, this rate still remains below the recommendations established by the Ministry of Health, which advocate that prenatal care must be properly provided to all pregnant women [28]. It is known that the notification rate of syphilis is considered to be an important indicator of accessibility and prenatal care quality [23]. However, despite the expansion of diagnosis and treatment in Brazil, increases in the number of cases indicates shortcomings in the efforts designed to control and prevent this STI [15]. At the same time, health authorities have also attributed increases in notification rates to the success of public health actions in improving detection rates. Nevertheless, actions designed to improve health care access for pregnant women have performed poorly in terms of CS prevention [21]. One of the main purposes of prenatal care is to assist women in a qualified and humanized way beginning in the early stages of pregnancy, adopting early screening procedures coupled with timely interventions [28]. Early diagnosis and treatment of SiP, ideally before the $20^{\text {th }}$ week of pregnancy, can reduce CS-related cases, such as miscarriages, stillbirths, and infant deaths [29]. It is therefore important that all pregnant women be tested at the first prenatal visit scheduled in the first trimester of pregnancy, with repeat testing performed at around 28 weeks and in the beginning of the third trimester in order to promptly implement appropriate therapy if necessary [30]. Information regarding CS vertical transmission should be provided to pregnant women at the onset of prenatal care, and physicians must inform patients regarding the risks and consequences of the disease to the mother and her fetus [24].

An established diagnosis does not guarantee adhesion to appropriate treatment by the patient. The late onset of symptoms (mostly detected in the third trimester), the interruption of and/or low attendance in prenatal examinations, difficulties in diagnosis, a lack of information regarding infection and unsafe sexual practices have been reported as risk factors for the development of syphilis [32-34]. Furthermore, errors in antibiotic dosage have also been of concern. Other key factors, such as conjugal infidelity, the absence of partners at prenatal appointments and reluctance in adhering to treatment protocols have also been reported by patients $[27,31]$.

Regarding the sociodemographic profile of pregnant women observed herein, most cases were identified among women aged 20-39 years who self-identified as 'mixed-race', had up to eight years of formal education and were mainly diagnosed with primary syphilis. However, it worth noting that many records contained missing race/ethnicity classification data in $\mathrm{P} 1$, which can be considered as a bias in the interpretation of our results. Indeed, the data presented herein corroborate other studies that identified a significant correlation between these sociodemographic characteristics and SiP [15,21-27,29,30,32-38]. We suggest that distinct strategies are required to reach more vulnerable populations and to minimize inequalities that enable greater access to health services. Poverty prompts specific vulnerabilities, whether behavioral or brought on by deficiencies in health services, such as prenatal care access and quality, which are also significantly associated with SiP. Brazilian social inequality in health supports the hypothesis that the prevalence of SiP is associated with a lower socioeconomic status [25,32,34].

Several child and maternal factors have been associated with increased risk and vulnerability to CS, such as race/ethnicity, socioeconomic status and maternal age [23]. In fact, STI and SiP were found to be more strongly associated with women who dropped out of school, self-identified as 'black' or 'mixed-race', were 
under 20 years of age or between 20 and 30 years old [30], had limited access to quality health services, preventive and educational programs or received assistance at public health care units, but without adequate prenatal care $[25,32,34]$. The association between younger mothers and CS strengthens the hypothesis that low-income adolescents are more vulnerable to STI and are at higher risk of teen pregnancy, as some authors have attributed this behavior to emotional and general immaturity $[30,38]$. A low education level is also considered a marker of greater risk exposure due to unawareness regarding the importance of prevention. In some settings in Brazil, higher frequencies of syphilis were diagnosed during the $2^{\text {nd }}$ and $3^{\text {rd }}$ trimesters of pregnancy, possibly related to (I) delayed initiation of prenatal care and (II) substandard quality of obstetric care [36]. These observations reaffirm the importance of early syphilis detection in pregnant women, as well as the availability of appropriate treatment women and their partners [36]. SiP control programs should place greater focus on these more vulnerable populations [32,34], especially considering that the lack of or inadequacies in public sexual education policies for younger individuals was associated with decreased condoms use in casual sexual relations in recent years [25].

The present study identified groups of municipalities with high rates of AS, CS, and SiP in Brazil. Between 2010 and 2018, higher numbers of AS cases were recorded throughout most of the country, especially in some southern and northern states. In addition, almost all microregions of the country reported a higher intensity of CS and SiP infections. Considering the epidemic profile of Brazil, we call attention to some priority areas in which intervention, such as appropriate patient management and effective infection control measures, could prove beneficial. The observed variations in notification rates among the municipalities may be the result of a decline in the underreporting of cases or reflect problems in local health systems, such as a lack of access to specialized services. Importantly, incomplete reporting hinders the elaboration of preventive strategies by policymakers, resulting in ineffective epidemiological surveillance $[26,39]$. It is evident that the Brazilian healthcare system will continue to be challenged by this scenario, as despite government investment in awareness campaigns, the circumstances remain far from ideal. Low adherence to treatment among patients and their partners is a main obstacle that must be overcome. Insufficient social awareness regarding prevention and treatment reflects the urgent need for educational policies aimed at preventing congenital infections $[25,26]$ in Brazil, especially in the affected macroregions and microregions identified in this study.

\section{Conclusion}

We conclude that despite the existence of control and awareness programs for STIs, current measures have proven ineffective in decreasing the notification rates of AS, CS and SiP in Brazil. Additionally, the underreporting of registered cases throughout the country results in biased data analysis. Considering the epidemiological profile of infection in Brazil, our results highlight the need to enhance preventive and control measures for eradication of syphilis.

\section{Abbreviations}


AC: Acre; Acquired Syphilis (AS); AIDS (Acquired Immunodeficiency Disease Syndrome); AL: Alagoas; AM: Amazonas; Annual Percentage Change (APC); AP: Amapá; BA: Bahia; Brazilian Institute of Geography and Statistics (IBGE); Brazilian National Notifiable Diseases Information System (SINAN); CE: Ceará; Congenital Syphilis (CS); DF: Distrito Federal; ES: Espírito Santo; GO: Goiás; MA: Maranhão; MG: Minas Gerais; Ministry of Health (MoH); MS: Mato Grosso do Sul; MT: Mato Grosso; PA: Pará; PB: Paraíba; PE: Pernambuco; PI: Piauí; PR: Paraná; RJ: Rio de Janeiro; RN: Rio Grande do Norte; RO: Rondônia; RR: Roraima; RS: Rio Grande do Sul; SC: Santa Catarina; SE: Sergipe; Sexually Transmitted Infection (STI); SP: São Paulo; Strengthening the Reporting of Observational studies in Epidemiology (STROBE); Syphilis in pregnant women (SiP); TO: Tocantins; Unified Health System (SUS); World Health Organization (WHO).

\section{Declarations}

\section{Acknowledgments}

We express our gratitude to Andris K. Walter for providing English language revision and manuscript copyediting assistance.

\section{Author's contributions}

FLNS and AAOS designed the study, and took lead in data collection, analysis, interpretation and drafting of the manuscript. FLNS, AAOS, WVS and CGRS participated in data collection, analysis, interpretation of the findings. FLNS, AAOS, WVS, CGRS LML, NEMF, RTD, EFS, LCMV and MFRG participated in data collection and manuscript writing. FLNS and CGRS supervised the manuscript writing, reviewed the manuscript for intellectual content and scientific integrity. All the authors reviewed the manuscript and approved it for publication.

\section{Funding}

This work was supported by the Gonçalo Moniz Institute (Fiocruz-BA), Coordination of Superior Level Staff Improvement-Brazil (CAPES - Finance Code 001), Research Support Foundation of the State of Bahia (FAPESB) and Inova Fiocruz/VPPCB (grant number VPPCB-008-FIO-18-2-20).

\section{Availability of data and materials}

All data presented in the study can be accessed in the SINAN and IBGE databases (available at http://datasus.saude.gov.br and http://www.ibge.gov.br, respectively). The datasets upon which our findings are based can be found in Additional files: File S1 (STROBE Checklist), File S2 (Sociodemographic variables of CS cases), File S3 (Sociodemographic variables of SiP cases), File S4 (Space and time distribution of reported numbers of AS cases), File S5 (Space and time distribution of reported numbers of CS cases), File S6 (Space and time distribution of reported numbers of SiP cases), File S7 (Spatial distribution of CS, AS and SiP cases).

\section{Ethics approval and consent to participate}


Not applicable.

\section{Consent for publication}

Not applicable.

\section{Competing interests}

The authors declare that they have no competing interests.

\section{References}

1. Mattei PL, Beachkofsky TM, Gilson RT, Wisco OJ. Syphilis: a reemerging infection. Am Fam Physician. 2012; 86(5): 433-40.

2. Newman L, Rowley J, Vander Hoorn S, Wijesooriya NS, Unemo M, Low N, et al. Global estimates of the prevalence and incidence of four curable sexually transmitted infections in 2012 based on systematic review and global reporting. PLoS One. 2015; 10(12): e0143304. https://doi.org/10.1371/journal.pone.0143304.

3. Ministry of Health. Clinical protocol and therapeutic guidelines for comprehensive care of people with sexually transmitted infections (STI). http://www.aids.gov.br/pt-br/pub/2015/protocolo-clinicoe-diretrizes-terapeuticas-para-atencao-integral-pessoas-com-infeccoes (2019). Accessed 9 Oct 2019.

4. Xu M, Xie Y, Jiang C, Xiao Y, Kuang X, Zhao F, et al. A novel ELISA using a recombinant outer membrane protein, rTp0663, as the antigen for serological diagnosis of syphilis. Int J Infect Dis. 2016; 43: 51-7. https://doi.org/10.1016/j.ijid.2015.12.013.

5. Stoltey JE, Cohen SE. Syphilis transmission: a review of the current evidence. Sex Health. 2015; 12(2): 103-9. https://doi.org/10.1071/SH14174.

6. Yu X, Zheng H. Syphilitic chancre of the lips transmitted by kissing: A case report and review of the literature. Medicine. 2016; 95(14): e3303. https://doi.org/10.1097/MD.0000000000003303.

7. Zhou P, Qian Y, Lu H, Guan Z. Nonvenereal transmission of syphilis in infancy by mouth-to-mouth transfer of prechewed food. Sex Transm Dis. 2009; 36(4): 216-7. https://doi.org/10.1097/OLQ.0b013e3181901c79.

8. Fanfair RN, Wallingford M, Long LL, Chi K-H, Pillay A, Chen C-Y, et al. Acquired macrolide-resistant Treponema pallidum after a human bite. Sex Transm Dis. 2014; 41(8): 493-5. https://doi.org/10.1097/OLQ.0000000000000156.

9. Ministry of Health. Epidemiological bulletin: syphilis 2017. http://www.aids.gov.br/ptbr/pub/2017/boletim-epidemiologico-de-sifilis-2017 (2017). Accessed 9 Oct 2019.

10. Norris SJ, Cox DL, Weinstock GM. Biology of Treponema pallidum: correlation of functional activities with genome sequence data. J Mol Microbiol Biotechnol. 2001; 3(1): 37-62.

11. Ministry of Health. Epidemiological bulletin: syphilis 2018. 2018. http://www.aids.gov.br/ptbr/pub/2018/boletim-epidemiologico-de-sifilis-2018 (2018). Accessed 9 Oct 2019. 
12. Santos CJ, Gomes B, Ribeiro Al. Mapping geographical patterns and high rate areas for sexually transmitted infections in Portugal: A retrospective study based on the national epidemiological surveillance system. Sex Transm Dis. 2020; 47(4): 261-8.

https://doi.org/1097/OLQ.0000000000001122.

13. Stamm LV. Syphilis: antibiotic treatment and resistance. Epidemiol Infect. 2015; 143(8): 1567-74. https://doi.org/10.1017/S0950268814002830.

14. Kitayama K, Segura ER, Lake JE, Perez-Brumer AG, Oldenburg CE, Myers BA, et al. Syphilis in the Americas: a protocol for a systematic review of syphilis prevalence and incidence in four high-risk groups, 1980-2016. Syst Rev. 2017; 6(1): 195. https://doi.org/10.1186/s13643-017-0595-3.

15. Souza JM, Giuffrida R, Ramos APM, Morceli G, Coelho, CH, Rodrigues MVP. Mother-to-child transmission and gestational syphilis: Spatial-temporal epidemiology and demographics in a Brazilian region. PLoS Negl Trop Dis. 2019; 13(2): e0007122. https://doi.org/10.1371/journal.pntd.0007122.

16. Ministry of Health. Epidemiological bulletin: syphilis 2016. http://www.aids.gov.br/ptbr/pub/2016/boletim-epidemiologico-de-sifilis-2016 (2016). Accessed 9 Dec 2019.

17. Ministry of Health. Health Surveillance in Brazil 2003-2019. http://www.saude.gov.br/boletinsepidemiologicos (2019). Accessed 9 Dec 2019.

18. Dantas DRG, Barros HST, Filho LFSM, Paranhos LDC, Calú MEC, Vilarim NT, et al. Prevalence of gestational and congenital syphilis in Brazil in the last 15 years. J Infect Dis Prev Med. 2018; 6(3). https://doi.org/10.4172/2329-8731.1000184.

19. Global Health Sector Strategy on Sexually Transmitted Infections 2016-2021. 2016 The WHO's strategy for STI treatment. https://www.who.int/reproductivehealth/publications/rtis/ghss-stis/en/ (2016). Accessed 9 Dec 2019.

20. Nyatsanza F, Tipple C. Syphilis: presentations in general medicine. Clin Med. 2016; 16(2): 184-8. https://doi.org/10.7861/clinmedicine.16-2-184.

21. Vargas L, Amaral S, Arriaga M, Sarno M, Brites C. High prevalence of syphilis in parturient women and congenital syphilis cases in public maternities in Salvador-Bahia, Brazil. BJOG. 2018; 125(10): 1212-4. https://doi.org/10.1111/1471-0528.15304.

22. Serafim AS, Moretti GP, Serafim GS, Niero CV, Rosa MI, Pires MMS, et al. Incidence of congenital syphilis in the south region of Brazil. Rev Soc Bras Med Trop. 2014; 47(2): 170-8. https://doi.org/10.1590/0037-8682-0045-2014.

23. Muricy CL, Júnior VLP. Congenital and maternal syphilis in the capital of Brazil. Rev Soc Bras Med Trop. 2015; 48(2): 216-9. https://doi.org/10.1590/0037-8682-0168-2014.

24. Fonseca SC, Oliveira LM, Almeida NMR, Silva KS, Kale PL. Incidence of congenital syphilis in a metropolitan region of Rio de Janeiro state: social inequalities. DST J Bras Doenças Sex Transm. 2013; 25(1): 21-5. https://doi.org/10.5533/DST-2177-8264-201325105.

25. Garbin AJI, Martins RJ, Belila NM, Exaltação SM, Garbin CAS. Reemerging diseases in Brazil: sociodemographic and epidemiological characteristics of syphilis and its under-reporting. Rev Soc 
Bras Med Trop. 2019; 52: e20180226. https://doi.org/10.1590/0037-8682-0226-2018.

26. Torres RG, Mendonça ALN, Montes GC, Manzan JJ, Ribeiro JU, Paschoini MC. Syphilis in pregnancy: the reality in a public hospital. Rev Bras Ginecol Obstet. 2019; 41(2): 90-6. https://doi.org/10.1055/s0038-1676569.

27. Cardoso ARP, Araújo MAL, Andrade RFV, Saraceni V, Miranda AE, Dourado MIC. Underreporting of congenital syphilis as a cause of fetal and infant deaths in northeastern Brazil. PLoS ONE. 2016; 11(12): e0167255. https://doi.org/10.1371/journal.pone.0167255.

28. Catunda HLO, Mendes IC, Oliveira ET, Bernardo EBR, Bezerra KC, Sousa DMN, et al. Epidemiological analysis of congenital syphilis in the state of Ceará, Brazil. J bras Doenças Sex Transm. 2013; 25(7): 7-12. https://doi.org/10.5533/DST-2177-8264-201325102.

29. Neto SES, Silva SSBE, Sartori AMC. Syphilis in pregnancy, congenital syphilis, and factors associated with mother-to-child transmission in Itapeva, São Paulo, 2010 to 2014. Rev Soc Bras Med Trop. 2018; 51(6): 819-26. https://doi.org/10.1590/0037-8682-0377-2017.

30. Padovani C, Oliveira RR, Pelloso SM. Syphilis in during pregnancy: association of maternal and perinatal characteristics in a region of southern Brazil. Rev Lat Am Enfermagem. 2018; 26: e3019. https://doi.org/10.1590/1518-8345.2305.3019.

31. Dong W, Zhou C, Rou KM, Wu ZY, Chen J, Scott SR, et al. A community-based comprehensive intervention to reduce syphilis infection among low-fee female sex workers in China: a matched-pair, community-based randomized study. Infect Dis Poverty. 2019; 8(1):97. https://doi.org/10.1186/s40249-019-0611-z.

32. Macêdo VC, Lira PIC, Frias PG, Romanguera LMD, Caires SFF, Ximenes RAA. Risk factors for syphilis in women: case-control study. Rev Saude Publica. 2017; 51: 78. https://doi.org/10.11606/S15188787.2017051007066.

33. Domingues RMSM, Saraceni V, Hartz ZMA, Leal MC. Congenital syphilis: a sentinel event in antenatal care quality. Rev Saude Publica. 2013; 47(1): 147-56. https://doi.org/10.1590/s003489102013000100019.

34. Domingues RMSM, Szwarcwald CL, Junior PRBS, Leal MC. Prevalence of syphilis in pregnancy and prenatal syphilis testing in Brazil: birth in Brazil study. Rev Saude Publica. 2014; 48(5): 766-74. https://doi.org/10.1590/s0034-8910.2014048005114.

35. Soeiro CM, Miranda AE, Saraceni V, Santos MC, Talhari S. Syphilis in pregnancy and congenital syphilis in Amazonas State, Brazil: an evaluation using database linkage. Cad. Saude Publica. 2014; 30(4): 715-23. https://doi.org/10.1590/0102-311x00156312.

36. Cavalcante PAM, Pereira RBL, Castro JGD. Syphilis in pregnancy and congenital syphilis in Palmas, Tocantins State, Brazil, 2007-2014. Epidemiol Serv Saude. 2017; 26(2): 255-64. https://doi.org/10.5123/S1679-49742017000200003.

37. Araújo MAL, Freitas SCR, Moura HJ, Gondim, APS, Silva RM. Prevalence and factors associated with syphilis in parturient women in Northeast, Brazil. BMC Public Health. 2013; 13: 206. https://doi.org/10.1186/1471-2458-13-206. 
38. Oliveira LR, Costa MCN, Barreto FR, Pereira SM, Dourado I, Teixeira MG. Evaluation of preventative and control measures for congenital syphilis in state of Mato Grosso. Rev Soc Bras Med Trop. 2014; 47(3): 334-40. https://doi.org/10.1590/0037-8682-0030-2014.

39. Martins-Melo FR, Alencar CH, Ramos Jr AN, Heukelbach J. Epidemiology of mortality related to Chagas' disease in Brazil, 1999-2007. PLoS Negl Trop Dis. 2012; 6(2): e1508. https://doi.org/10.1371/journal.pntd.0001508.

\section{Figures}

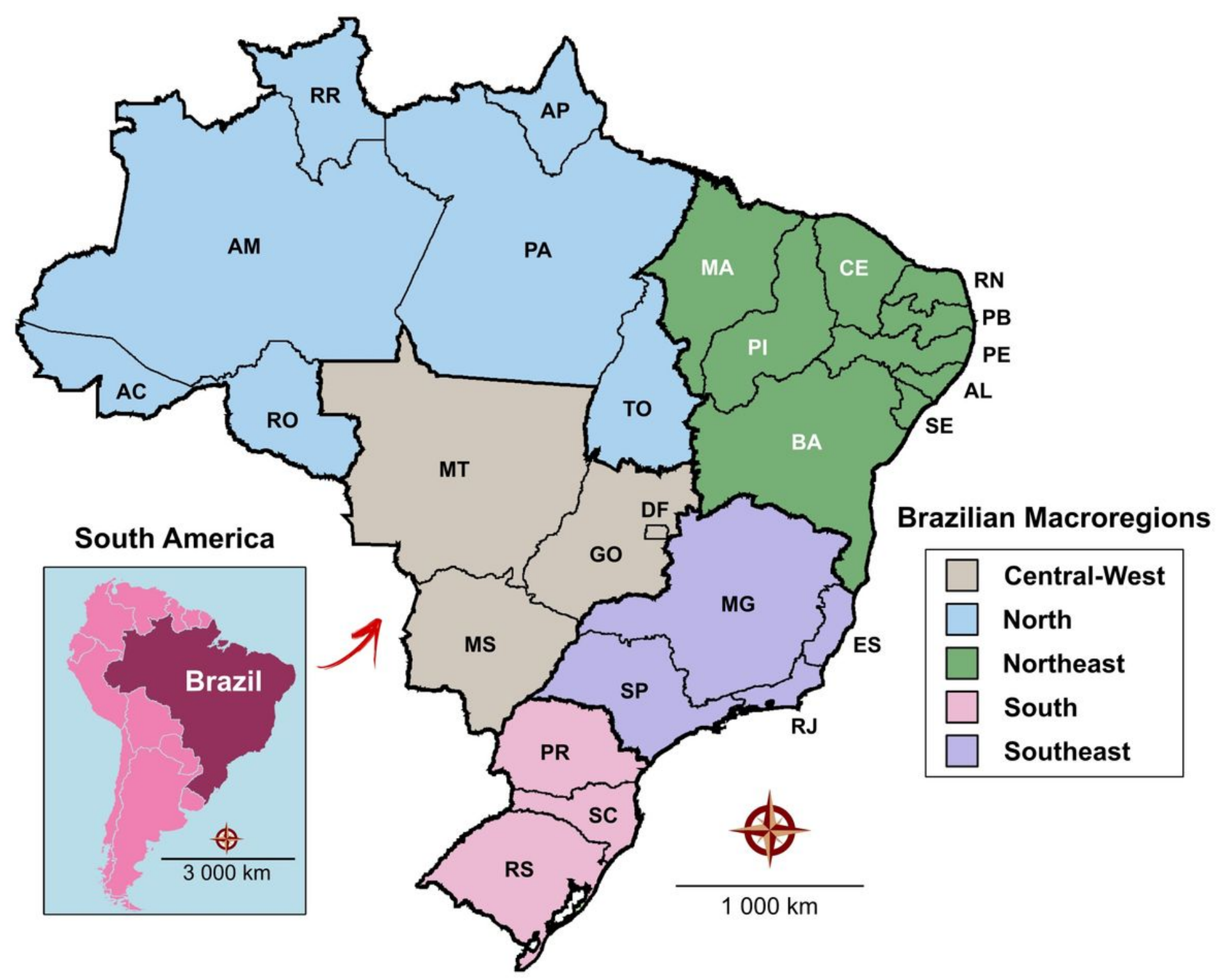

Figure 1

Geographic division of Brazil into five macroregions, 26 states and a Federal District (DF). Macroregions and corresponding state abbreviations. Digital maps in the public domain were obtained from IBGE cartographic database in shapefile format (.shp), which was subsequently reformatted and analyzed 
using QGIS version 3.10 Note: The designations employed and the presentation of the material on this map do not imply the expression of any opinion whatsoever on the part of Research Square concerning the legal status of any country, territory, city or area or of its authorities, or concerning the delimitation of its frontiers or boundaries. This map has been provided by the authors.

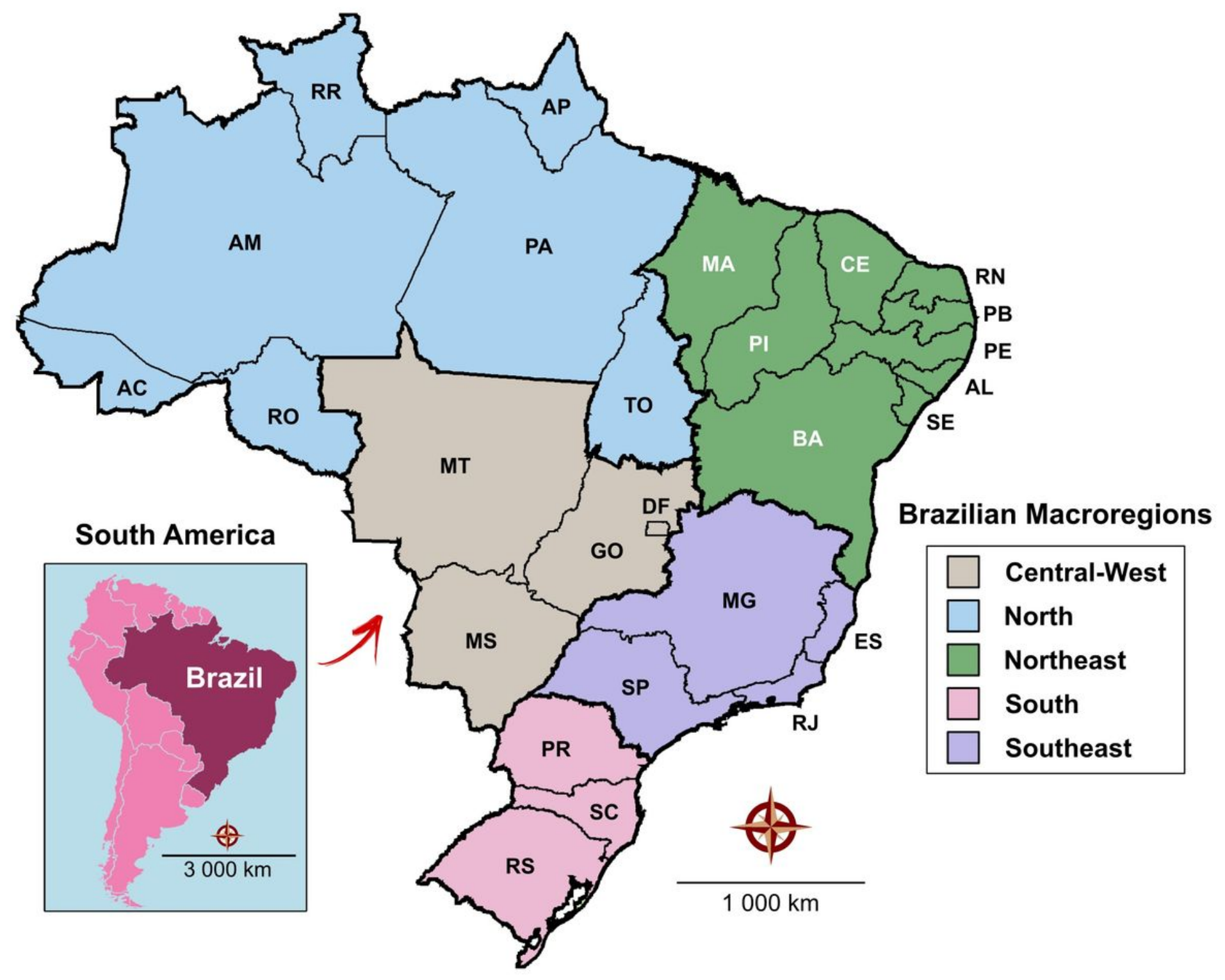

\section{Figure 1}

Geographic division of Brazil into five macroregions, 26 states and a Federal District (DF). Macroregions and corresponding state abbreviations. Digital maps in the public domain were obtained from IBGE cartographic database in shapefile format (.shp), which was subsequently reformatted and analyzed using QGIS version 3.10 Note: The designations employed and the presentation of the material on this map do not imply the expression of any opinion whatsoever on the part of Research Square concerning the legal status of any country, territory, city or area or of its authorities, or concerning the delimitation of its frontiers or boundaries. This map has been provided by the authors. 


\section{A - Congenital syphilis}

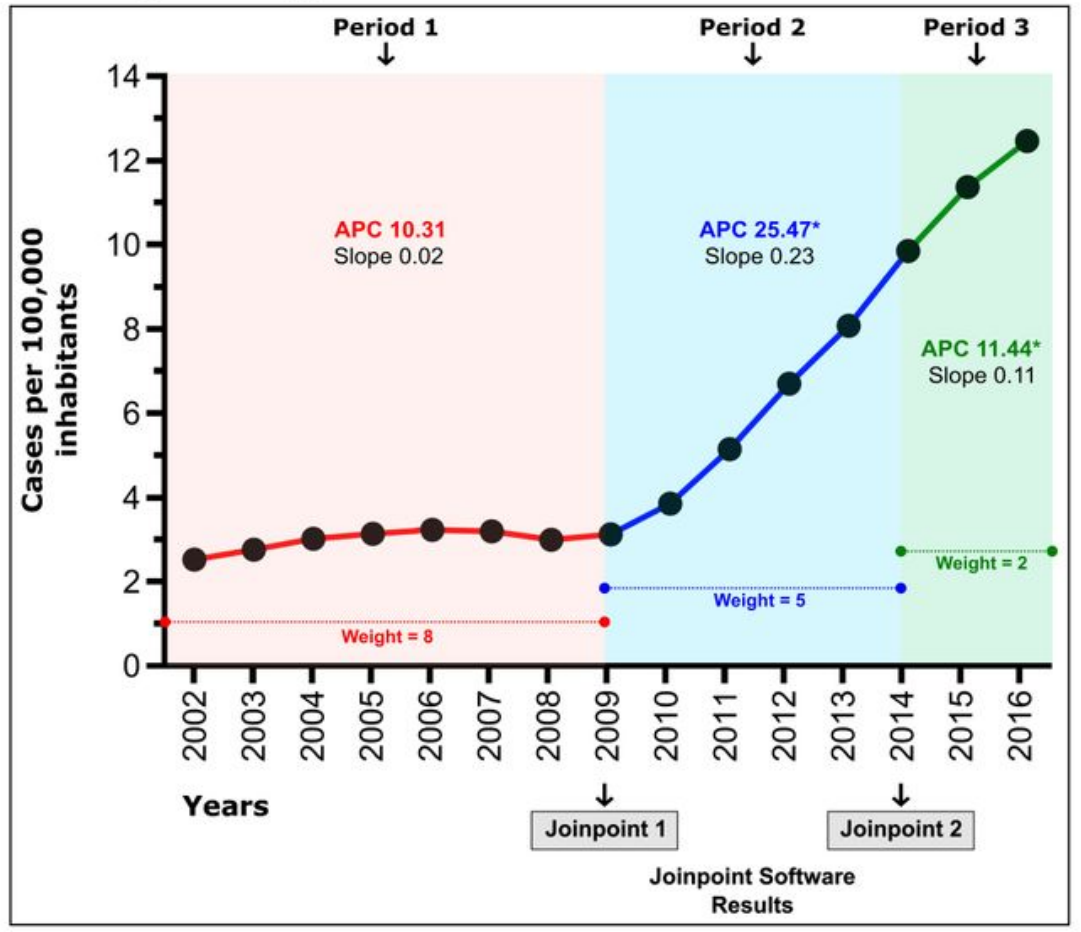

\section{B - Syphilis in pregnancy}

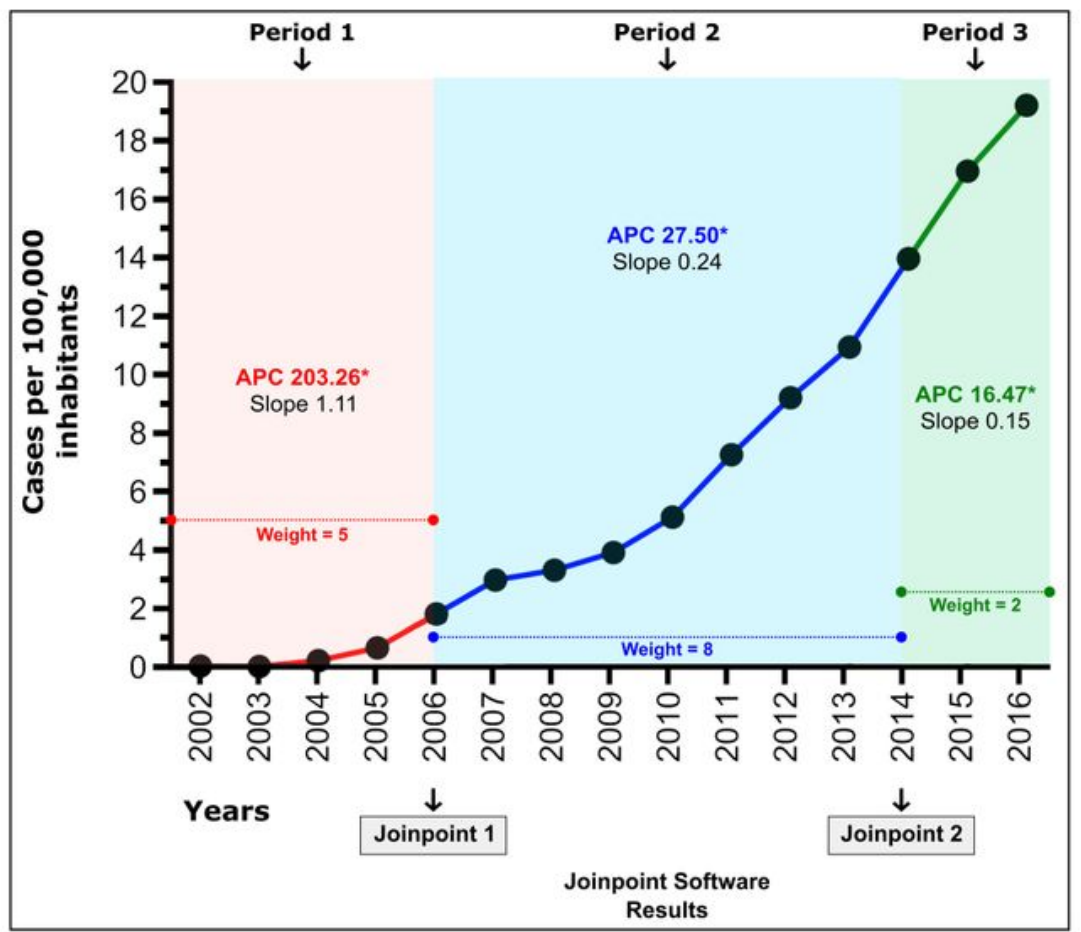

\section{Figure 2}

Global incidence in Brazil per 100,000 inhabitants of CS (A) and SiP (B) according to SINAN. Joinpoint regression analysis using APC (Annual Percentage Change) calculations identified three distinct periods for each form of syphilis. 


\section{A - Congenital syphilis}

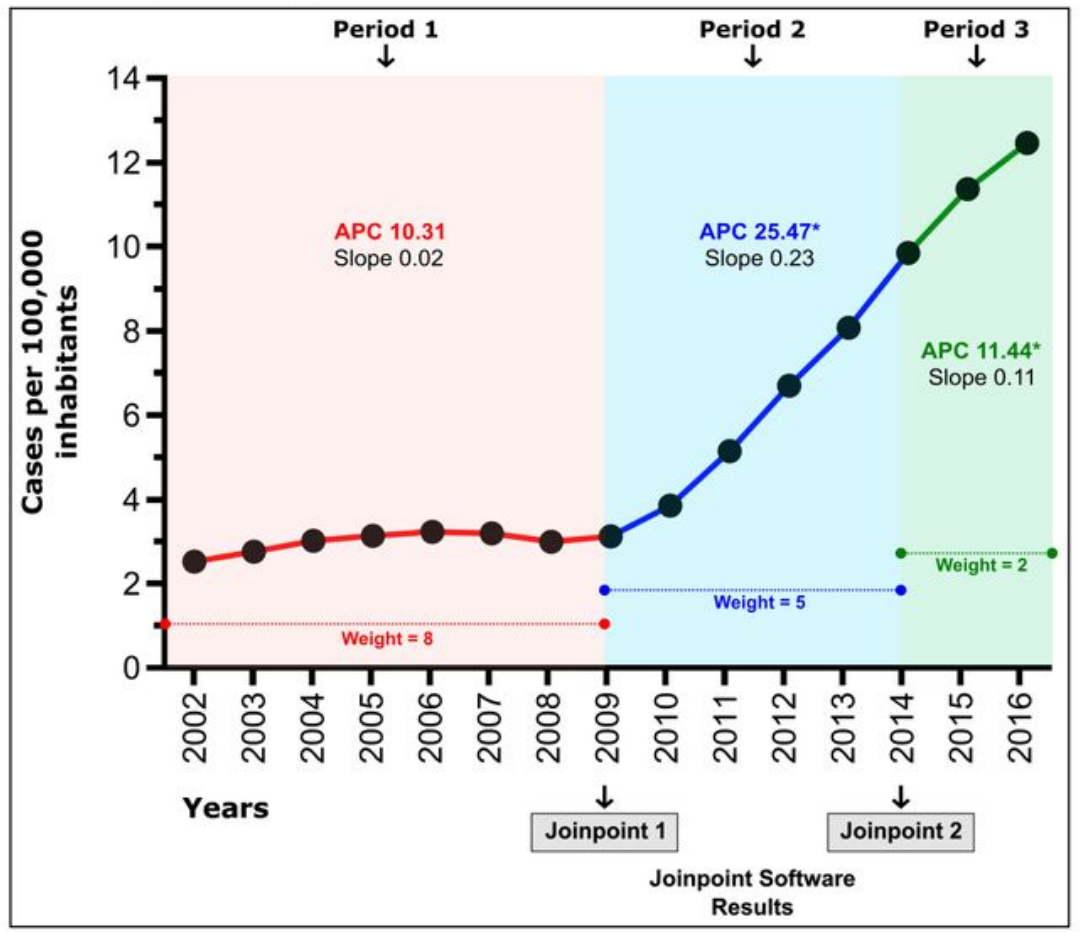

\section{B - Syphilis in pregnancy}

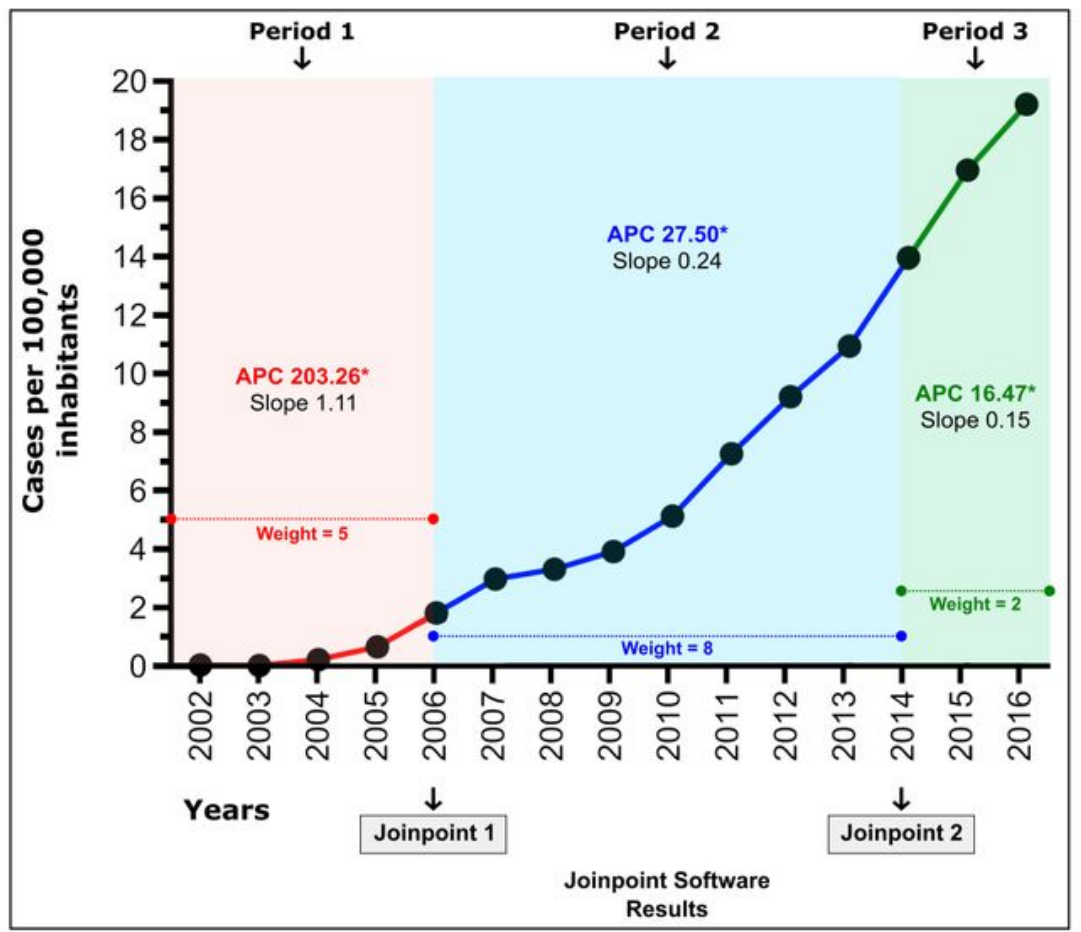

Figure 2

Global incidence in Brazil per 100,000 inhabitants of CS (A) and SiP (B) according to SINAN. Joinpoint regression analysis using APC (Annual Percentage Change) calculations identified three distinct periods for each form of syphilis. 


\section{Congenital syphilis}
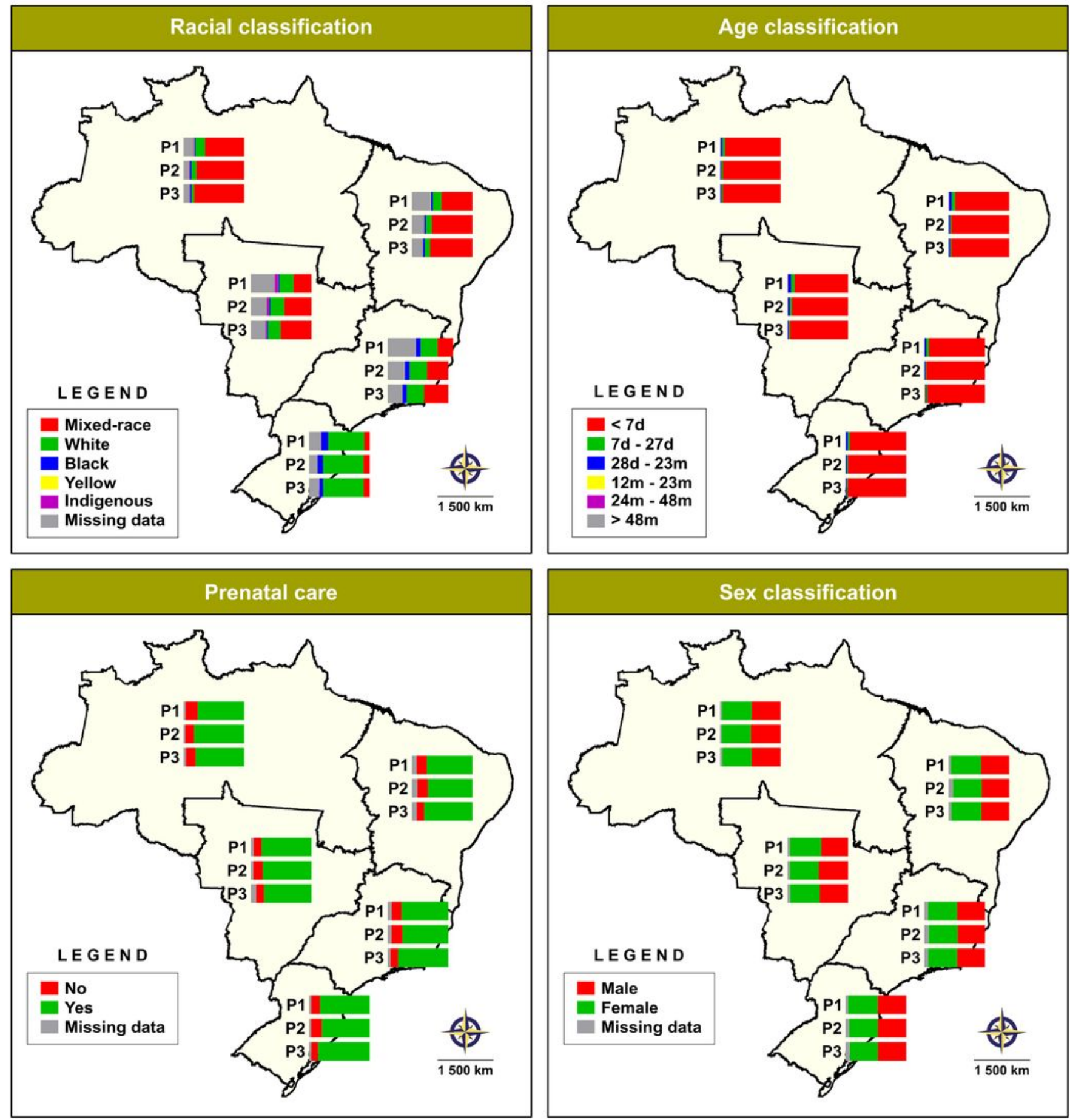

Figure 3

Analysis of changes in sociodemographic variables by region, stratified according to three periods of CS notifications. Digital maps in the public domain were obtained from IBGE cartographic database in shapefile format (.shp), which was subsequently reformatted and analyzed using QGIS version 3.10. Note: The designations employed and the presentation of the material on this map do not imply the expression of any opinion whatsoever on the part of Research Square concerning the legal status of any 
country, territory, city or area or of its authorities, or concerning the delimitation of its frontiers or boundaries. This map has been provided by the authors.

\section{Congenital syphilis}
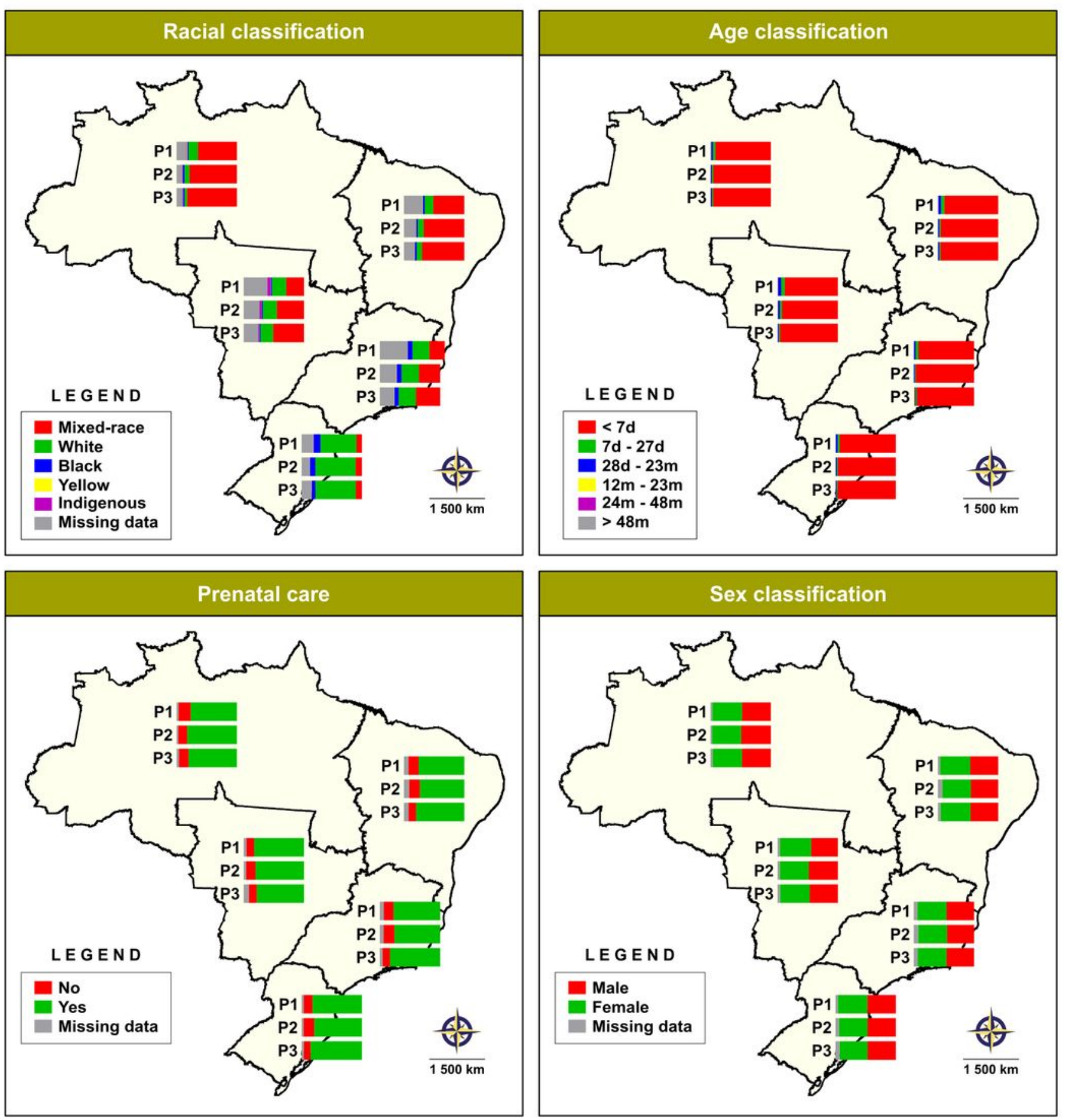

Figure 3

Analysis of changes in sociodemographic variables by region, stratified according to three periods of CS notifications. Digital maps in the public domain were obtained from IBGE cartographic database in shapefile format (.shp), which was subsequently reformatted and analyzed using QGIS version 3.10. 
Note: The designations employed and the presentation of the material on this map do not imply the expression of any opinion whatsoever on the part of Research Square concerning the legal status of any country, territory, city or area or of its authorities, or concerning the delimitation of its frontiers or boundaries. This map has been provided by the authors.
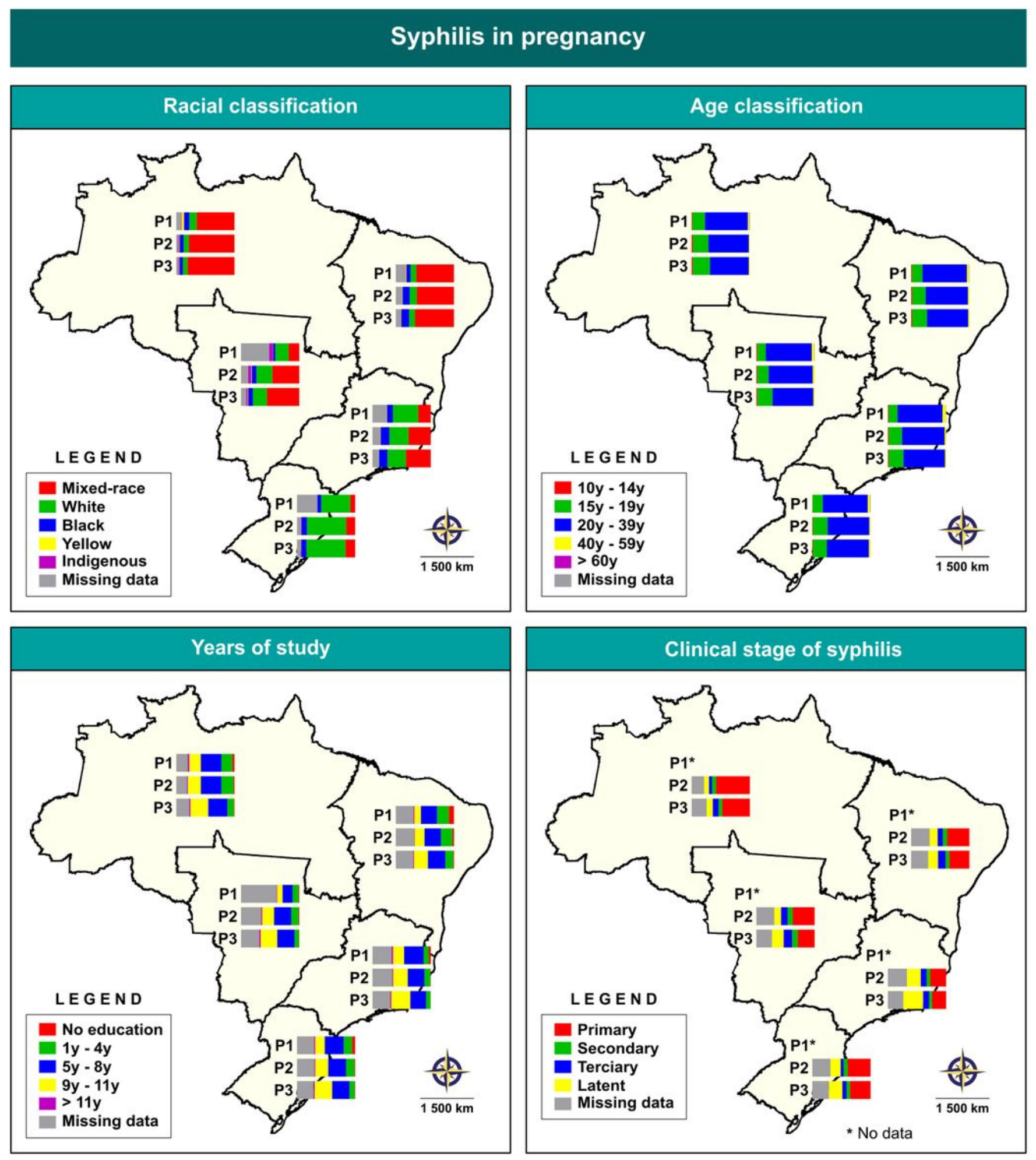

Figure 4 
Analysis of changes in sociodemographic profile by region, stratified according to three periods of SiP notifications. P1*: data not available. Digital maps in the public domain were obtained IBGE cartographic database in shapefile format (.shp), which was subsequently reformatted and analyzed using QGIS version 3.10. Note: The designations employed and the presentation of the material on this map do not imply the expression of any opinion whatsoever on the part of Research Square concerning the legal status of any country, territory, city or area or of its authorities, or concerning the delimitation of its frontiers or boundaries. This map has been provided by the authors.

\section{Syphilis in pregnancy}
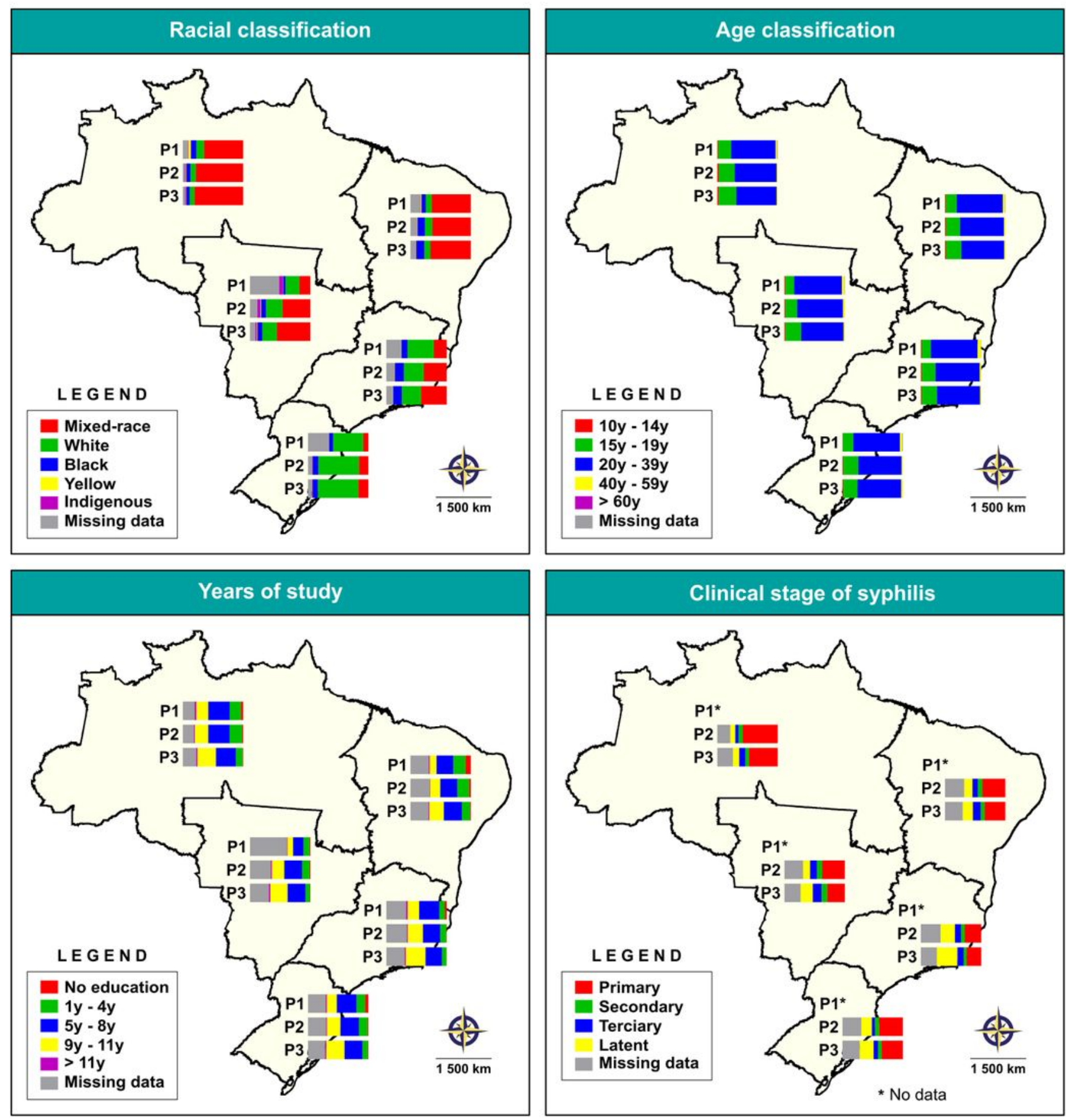


\section{Figure 4}

Analysis of changes in sociodemographic profile by region, stratified according to three periods of SiP notifications. P1*: data not available. Digital maps in the public domain were obtained IBGE cartographic database in shapefile format (.shp), which was subsequently reformatted and analyzed using QGIS version 3.10. Note: The designations employed and the presentation of the material on this map do not imply the expression of any opinion whatsoever on the part of Research Square concerning the legal status of any country, territory, city or area or of its authorities, or concerning the delimitation of its frontiers or boundaries. This map has been provided by the authors.
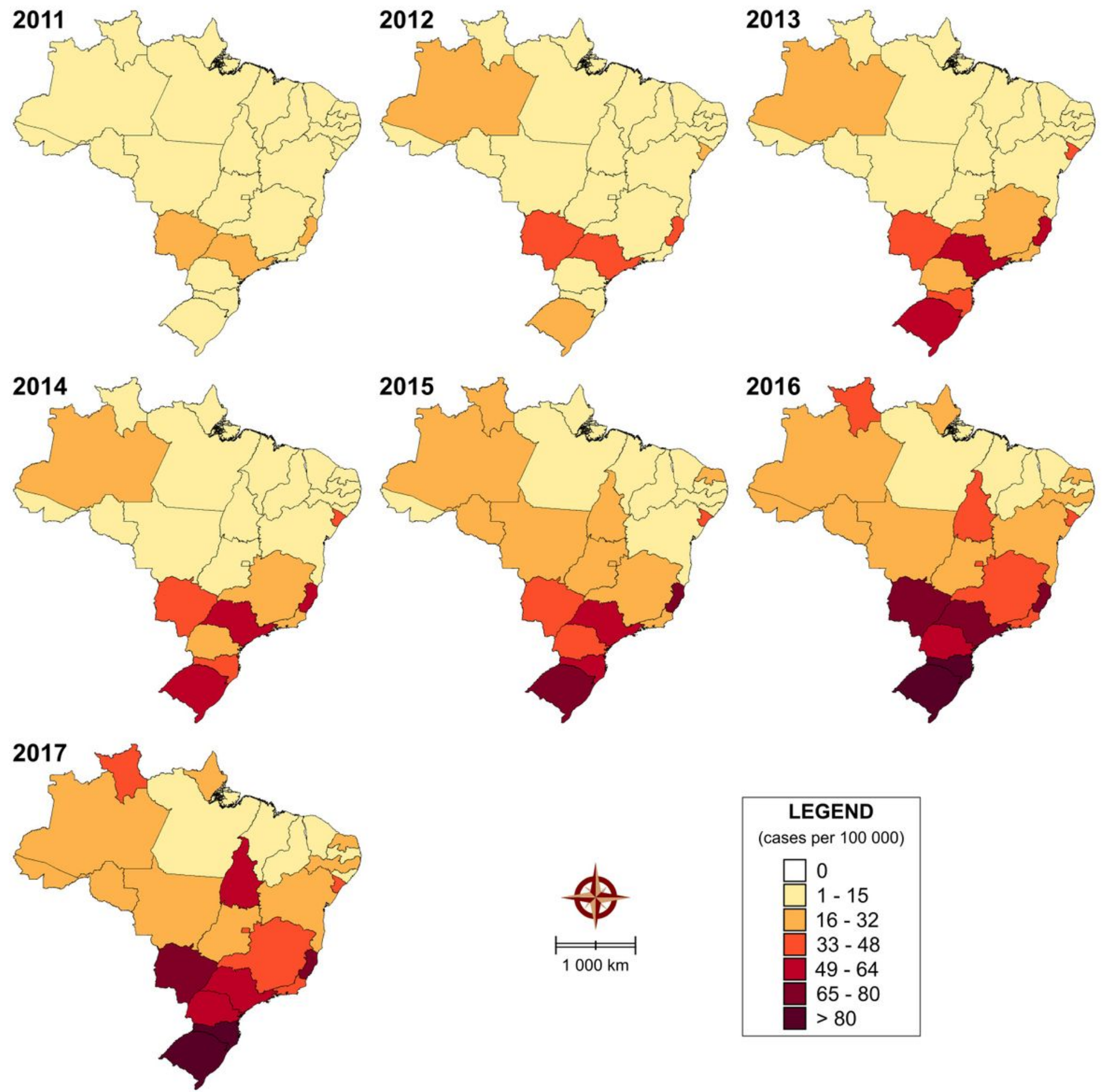


\section{Figure 5}

Space and time distribution of AS cases (2010 to 2018) in Brazil, based on cases by state. Digital maps in the public domain were obtained from IBGE cartographic database in shapefile format (.shp), which was subsequently reformatted and analyzed using QGIS version 3.10. Note: The designations employed and the presentation of the material on this map do not imply the expression of any opinion whatsoever on the part of Research Square concerning the legal status of any country, territory, city or area or of its authorities, or concerning the delimitation of its frontiers or boundaries. This map has been provided by the authors.
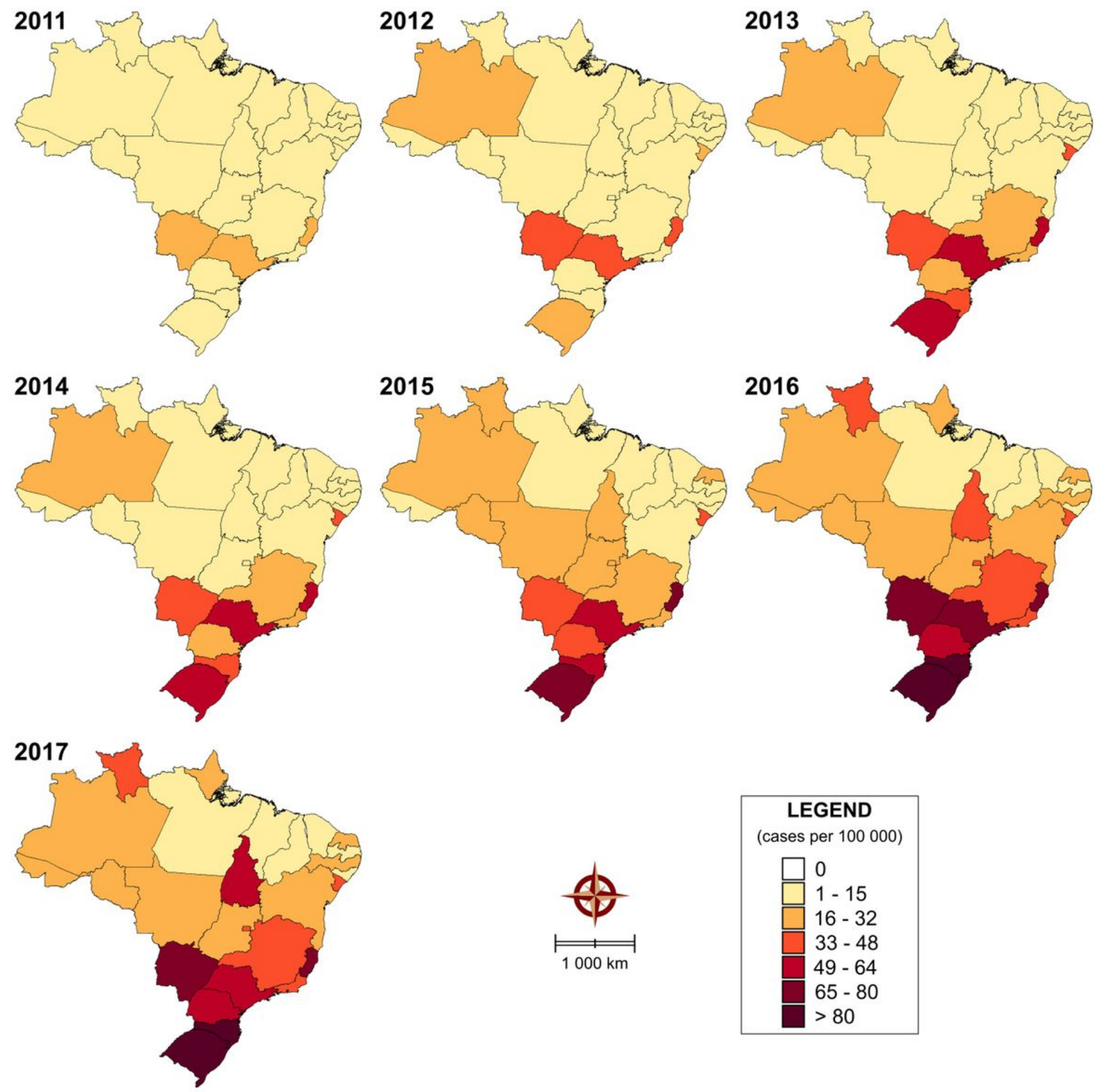


\section{Figure 5}

Space and time distribution of AS cases (2010 to 2018) in Brazil, based on cases by state. Digital maps in the public domain were obtained from IBGE cartographic database in shapefile format (.shp), which was subsequently reformatted and analyzed using QGIS version 3.10. Note: The designations employed and the presentation of the material on this map do not imply the expression of any opinion whatsoever on the part of Research Square concerning the legal status of any country, territory, city or area or of its authorities, or concerning the delimitation of its frontiers or boundaries. This map has been provided by the authors. 
2002

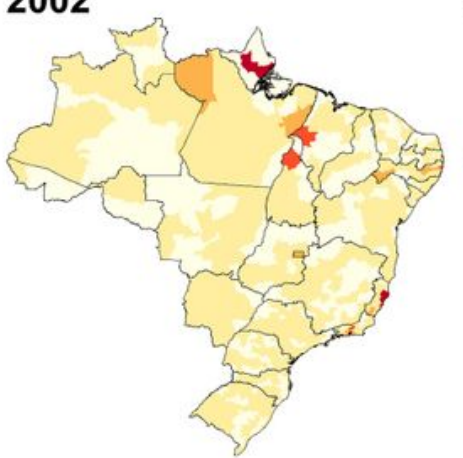

2006

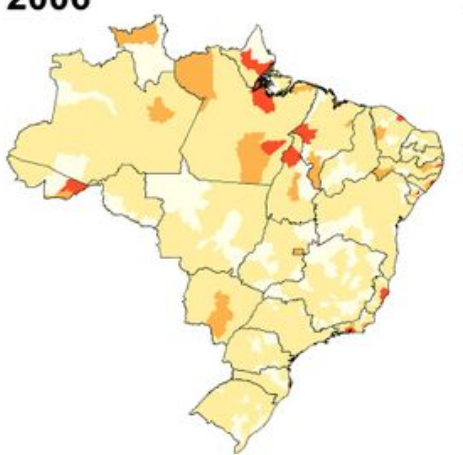

2010

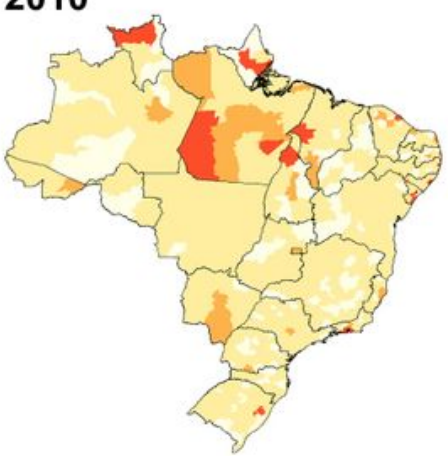

2014

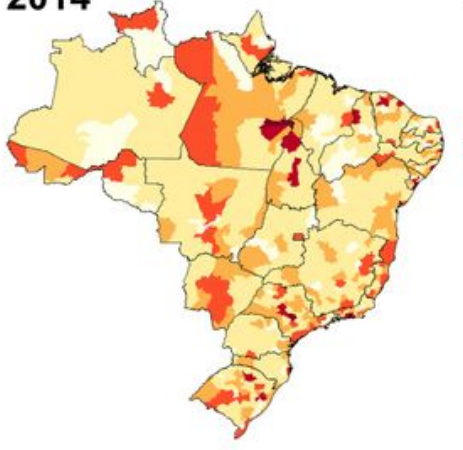

2003

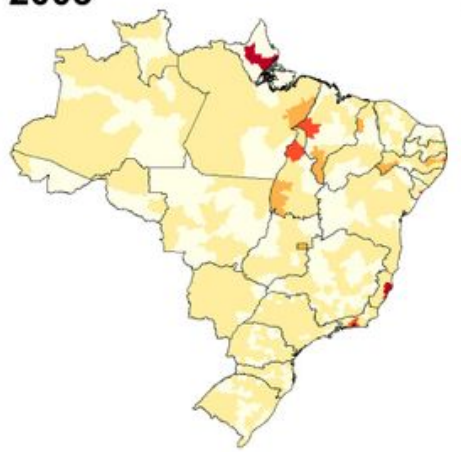

2007

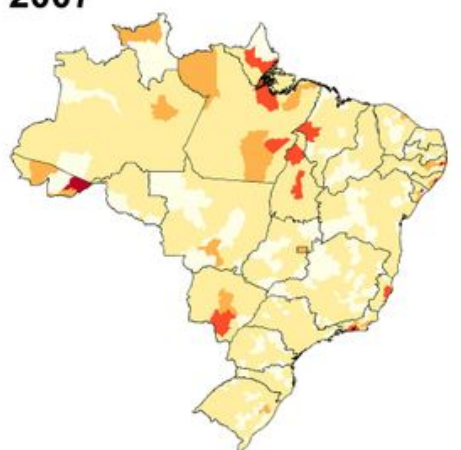

2011

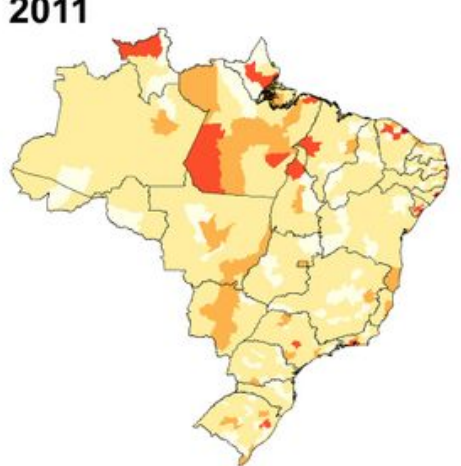

2015
2004

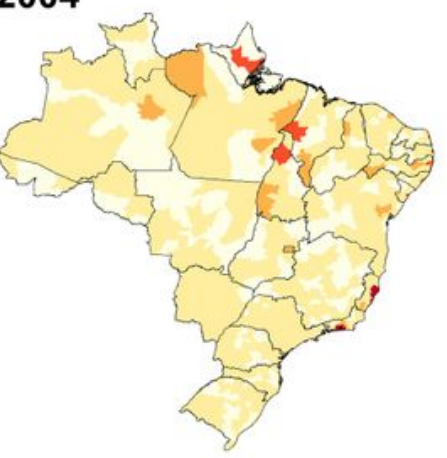

2008

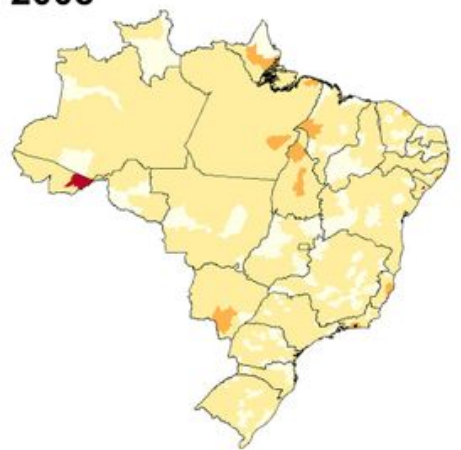

2012

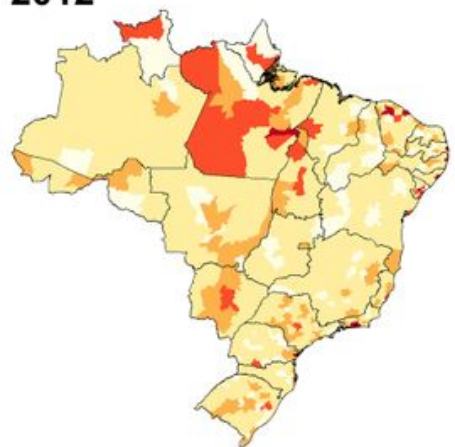

2016

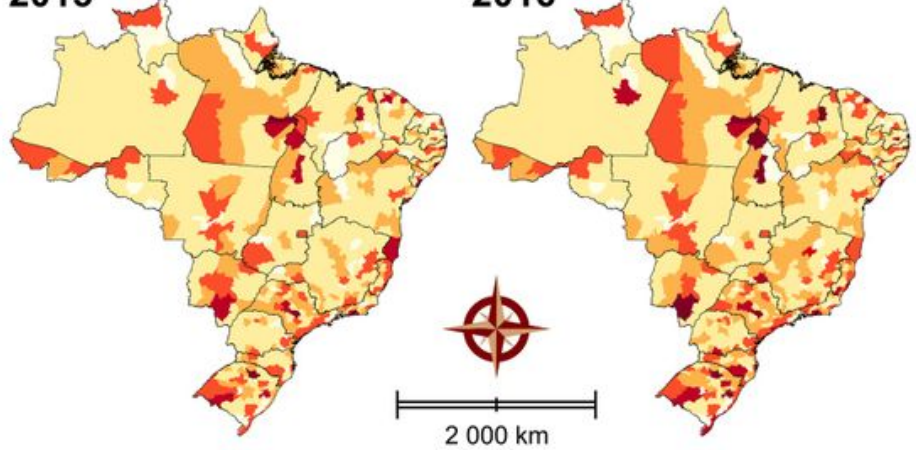

2005

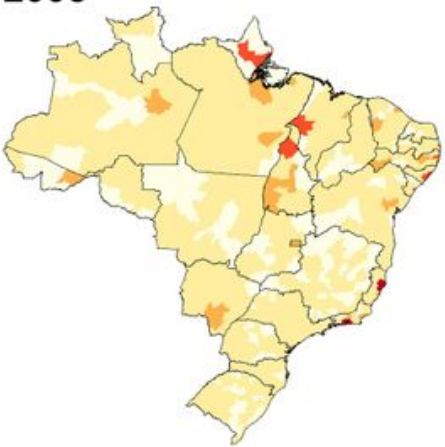

2009

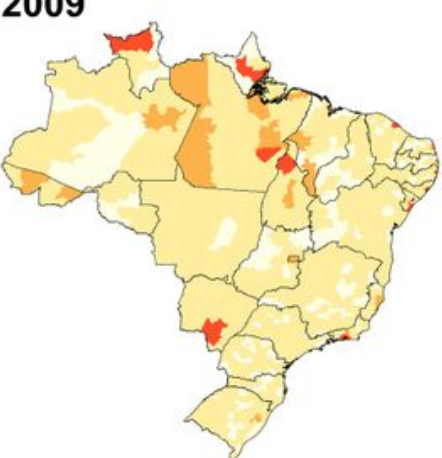

2013

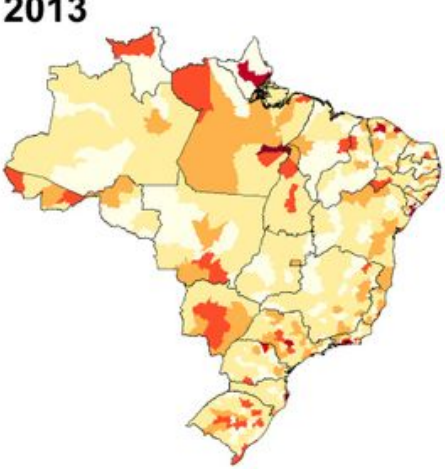

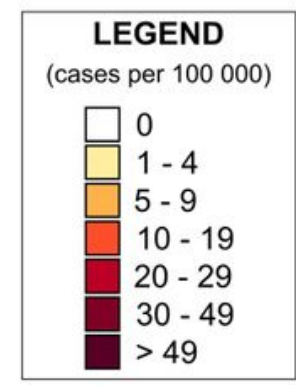

\section{Figure 6}

Space and time distribution of CS cases (2001 to 2017) in Brazil, based on cases by microregions. Digital maps in the public domain were obtained from IBGE cartographic database in shapefile format (.shp), which was subsequently reformatted and analyzed using QGIS version 3.10. Note: The designations employed and the presentation of the material on this map do not imply the expression of any opinion whatsoever on the part of Research Square concerning the legal status of any country, territory, city or 
area or of its authorities, or concerning the delimitation of its frontiers or boundaries. This map has been provided by the authors.
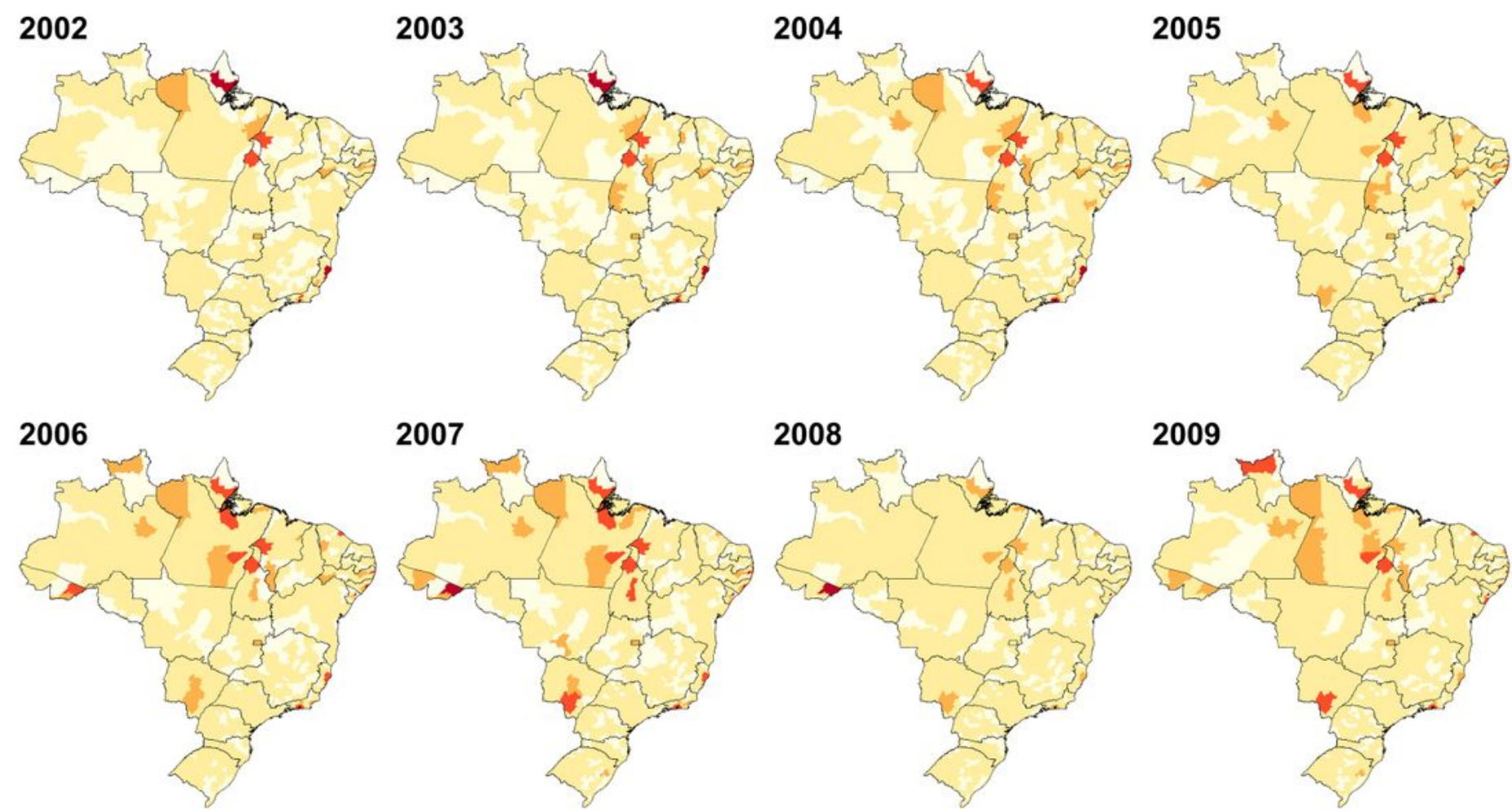

2007

2008
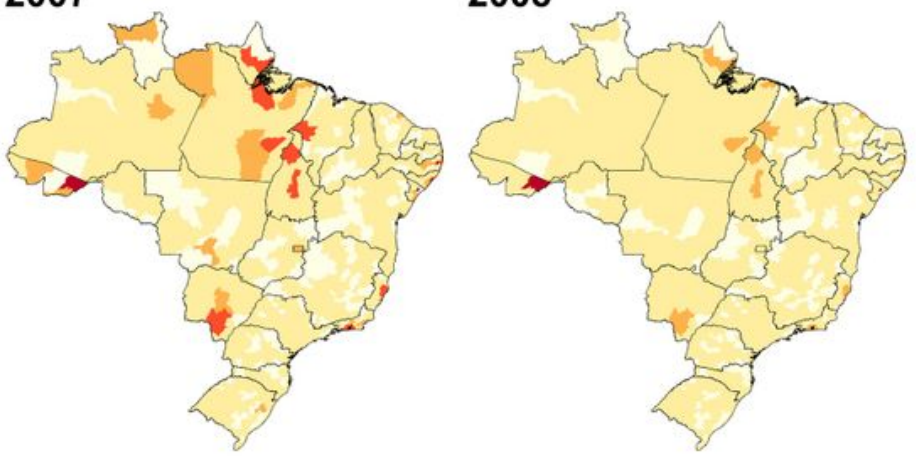

2009

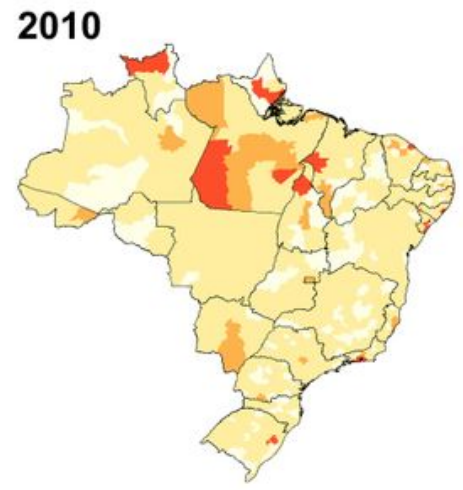

2011

2012
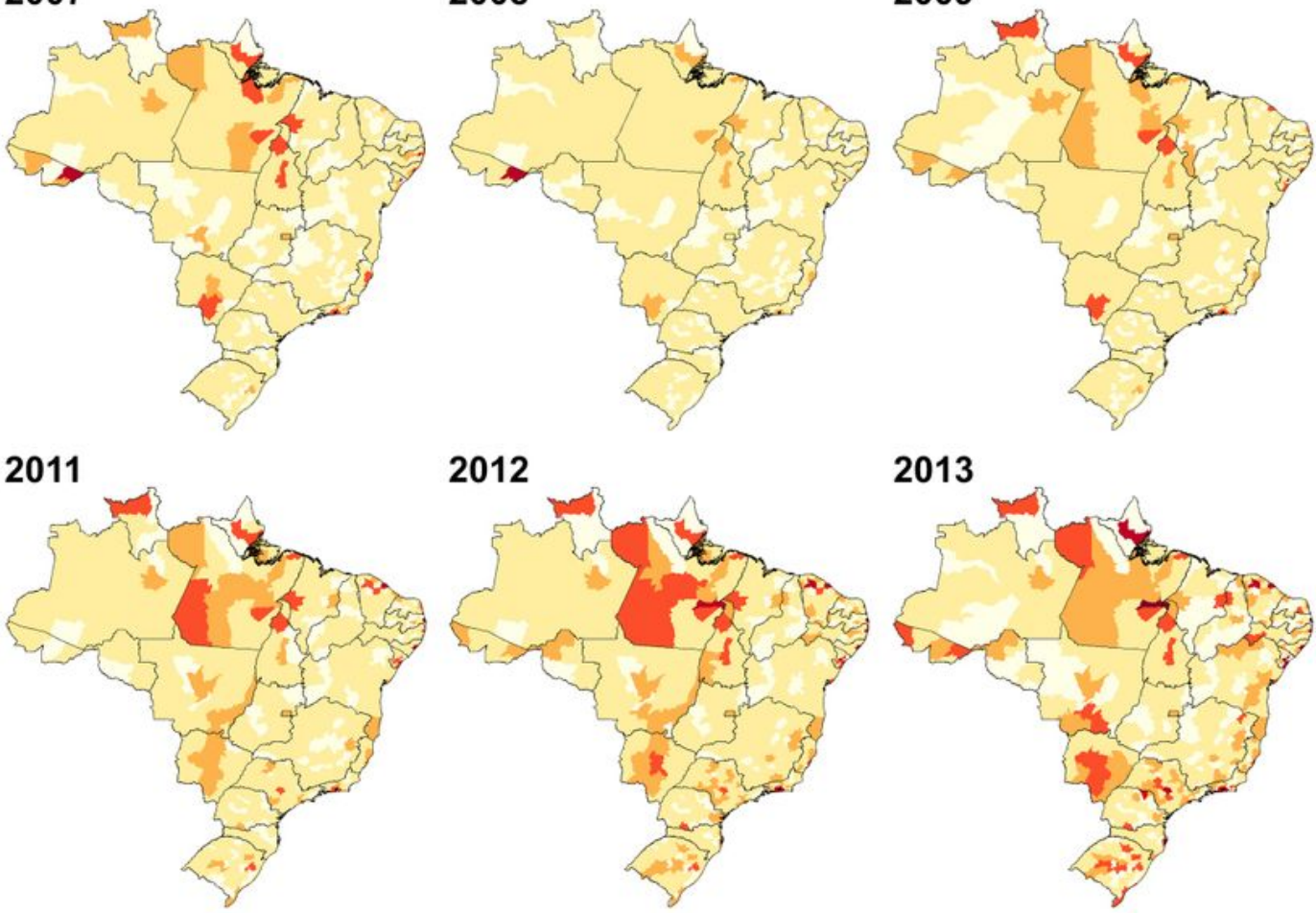

2013
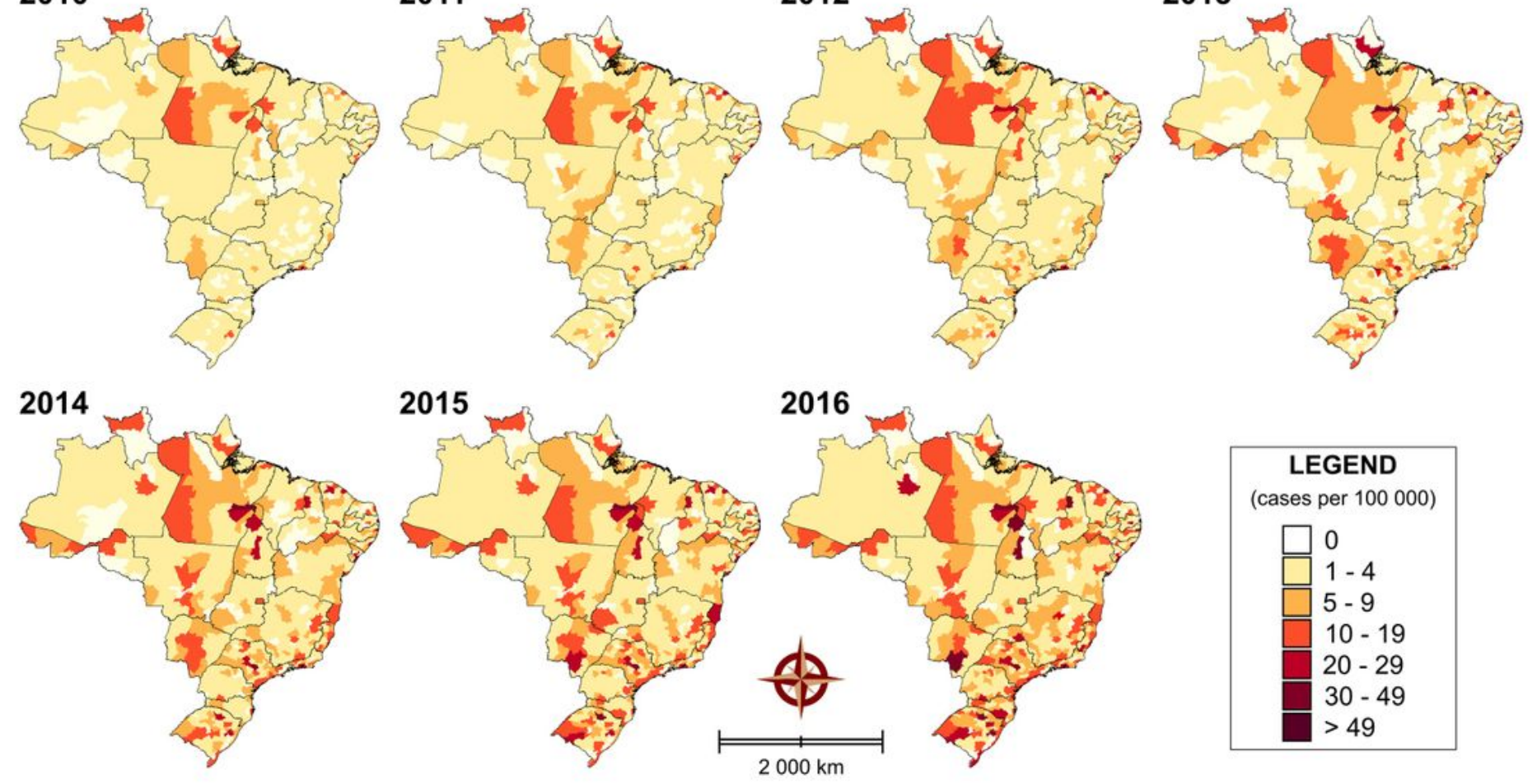

2015

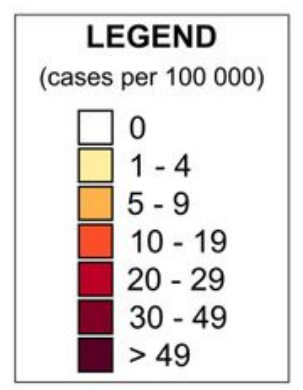

Figure 6

Space and time distribution of CS cases (2001 to 2017) in Brazil, based on cases by microregions. Digital maps in the public domain were obtained from IBGE cartographic database in shapefile format (.shp), which was subsequently reformatted and analyzed using QGIS version 3.10. Note: The designations 
employed and the presentation of the material on this map do not imply the expression of any opinion whatsoever on the part of Research Square concerning the legal status of any country, territory, city or area or of its authorities, or concerning the delimitation of its frontiers or boundaries. This map has been provided by the authors.

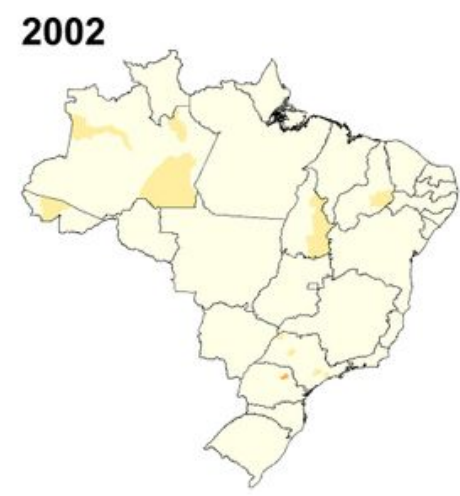

2006

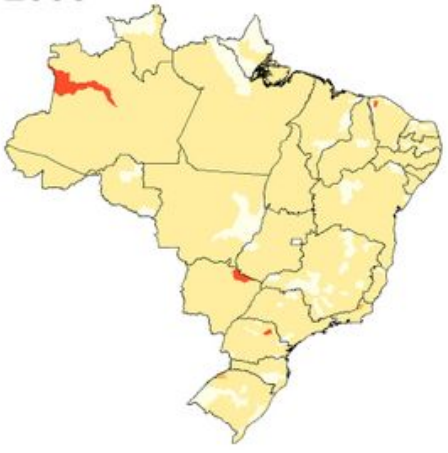

2010

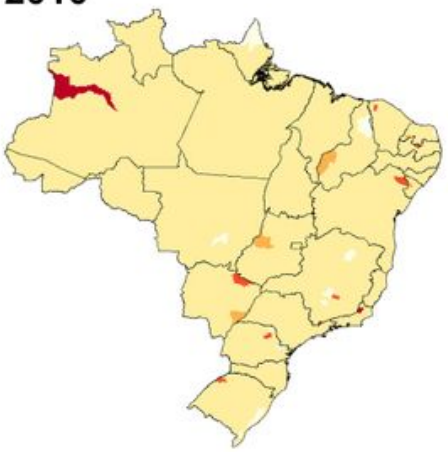

2014

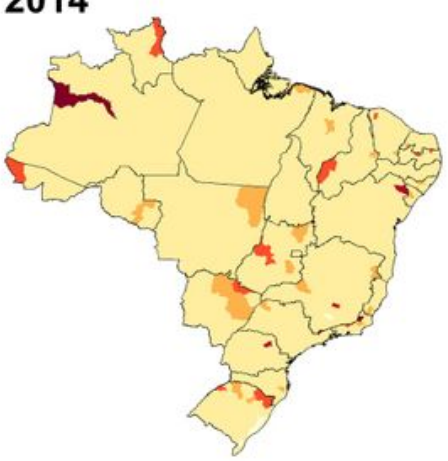

2003

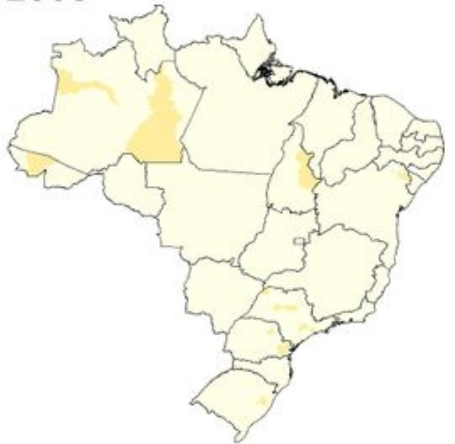

2007

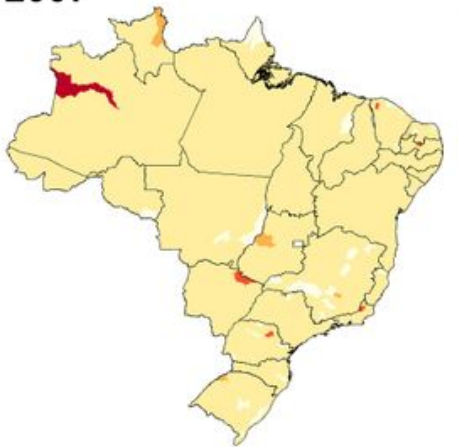

2011

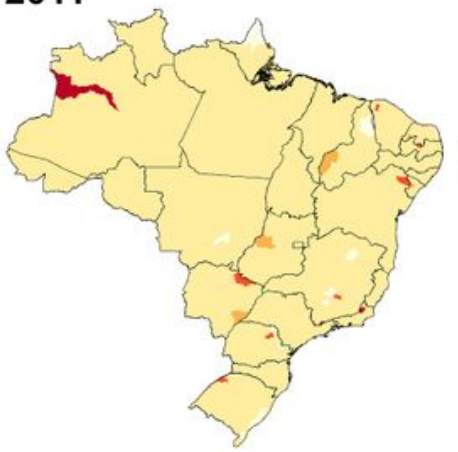

2015

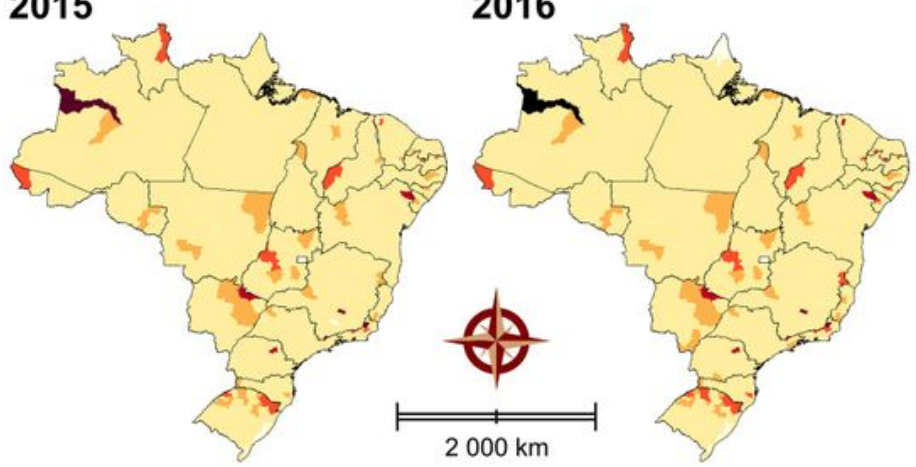

2005
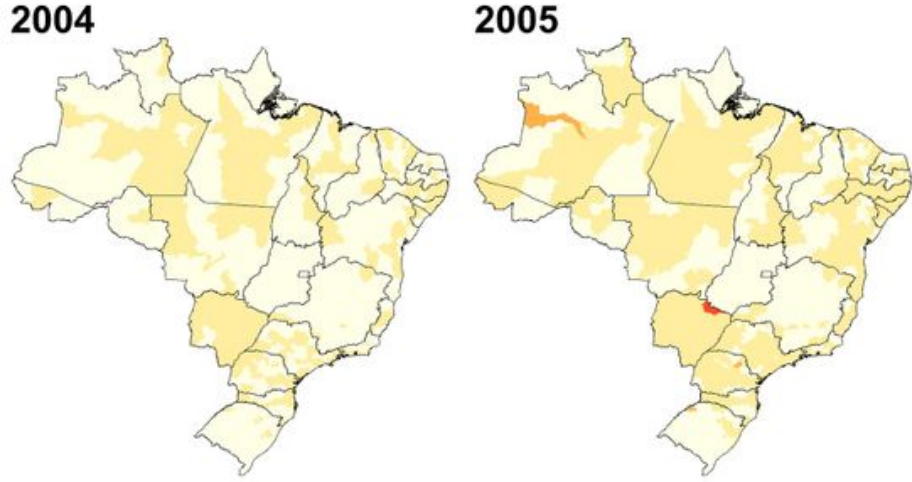

2009

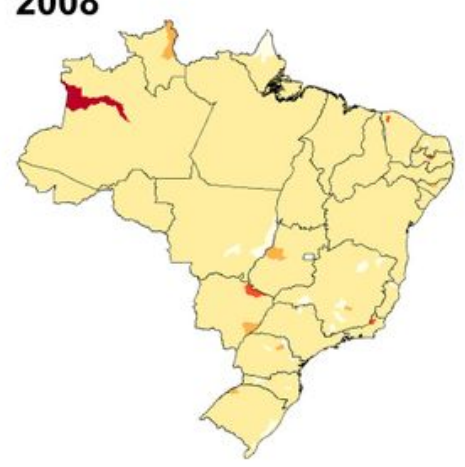

2012

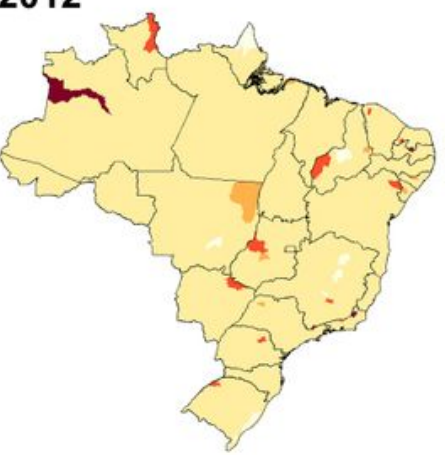

2013

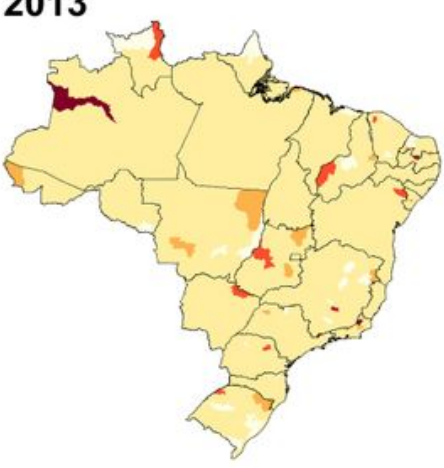

Figure 7 
Space and time distribution of SiP cases (2001 to 2017) in Brazil, based on cases by microregions. Digital maps in the public domain were obtained from IBGE cartographic database in shapefile format (.shp), which was subsequently reformatted and analyzed using QGIS version 3.10. Note: The designations employed and the presentation of the material on this map do not imply the expression of any opinion whatsoever on the part of Research Square concerning the legal status of any country, territory, city or area or of its authorities, or concerning the delimitation of its frontiers or boundaries. This map has been provided by the authors.

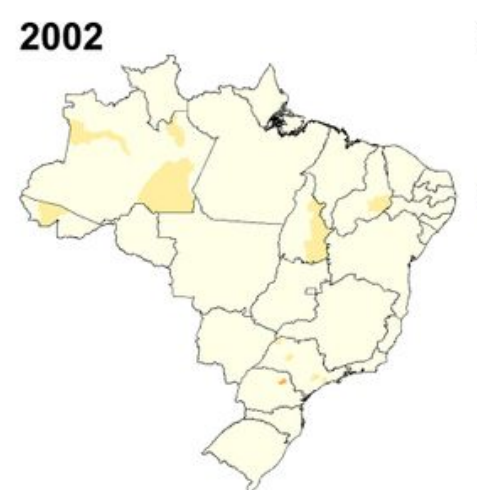

2006

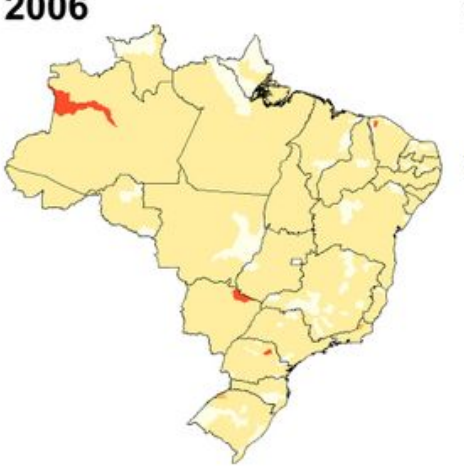

2010

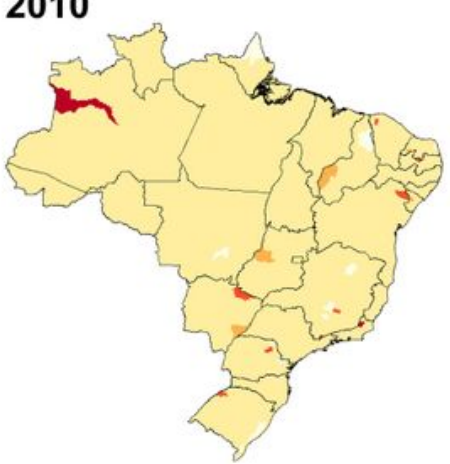

2014

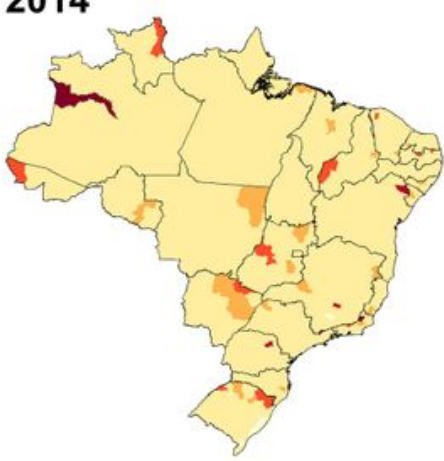

2003

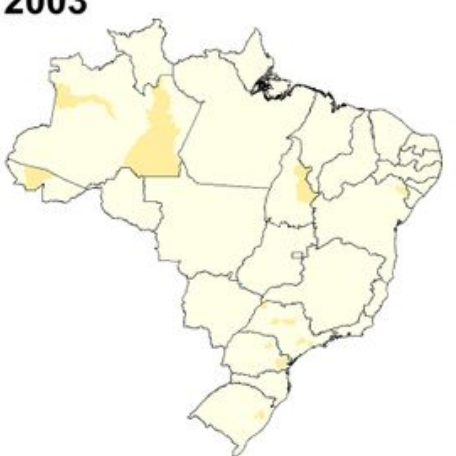

2007

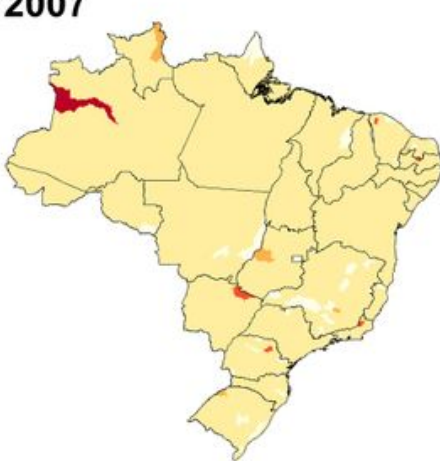

2011

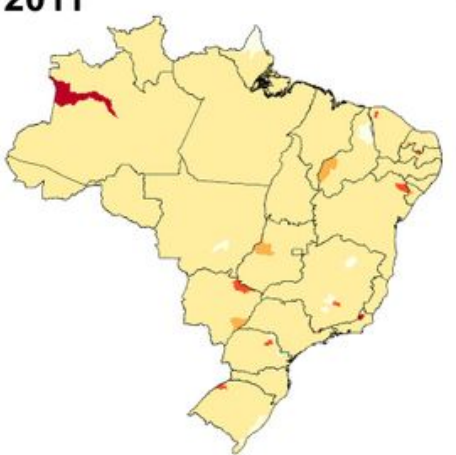

2015

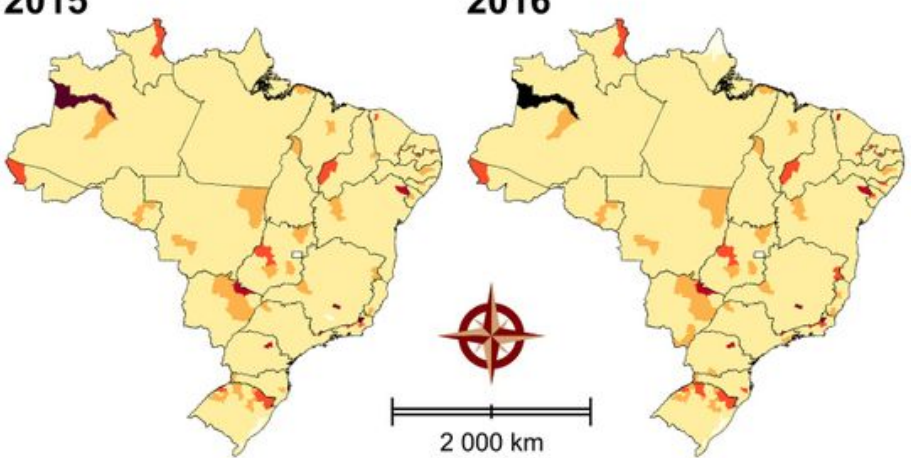

2005

2004

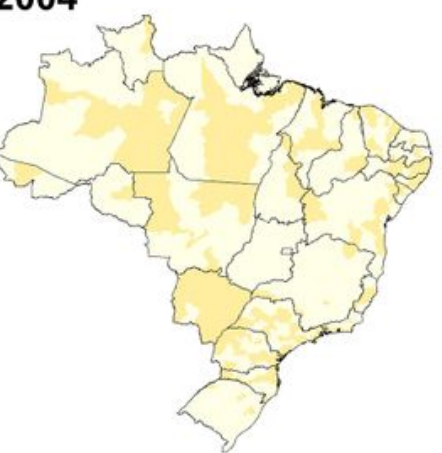

2008

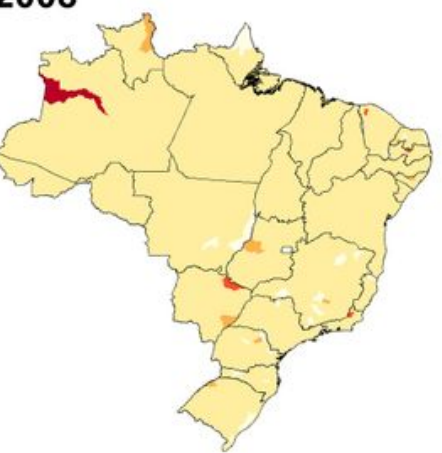

2012

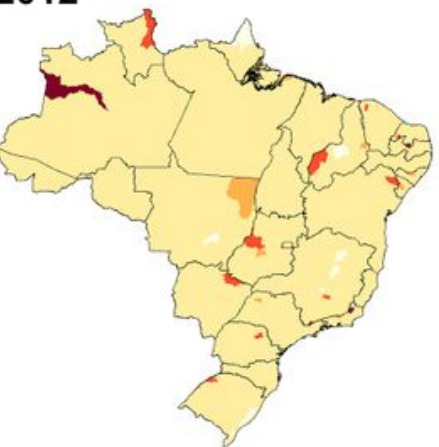

2013

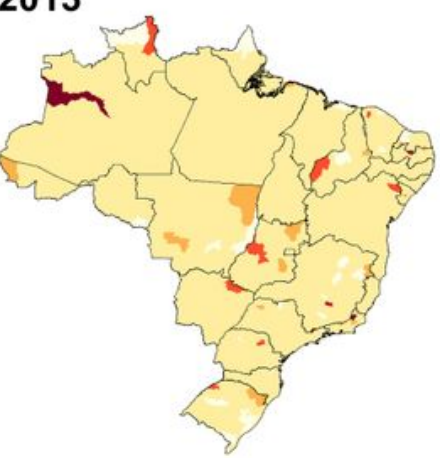

2009

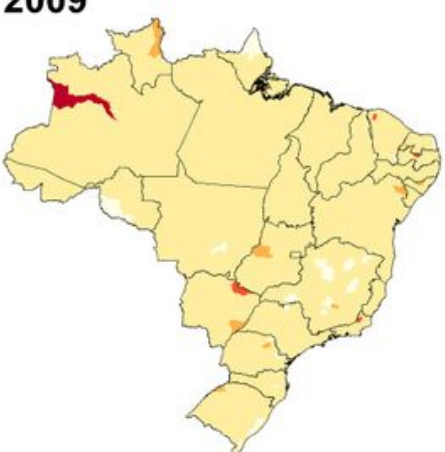




\section{Figure 7}

Space and time distribution of SiP cases (2001 to 2017) in Brazil, based on cases by microregions. Digital maps in the public domain were obtained from IBGE cartographic database in shapefile format (.shp), which was subsequently reformatted and analyzed using QGIS version 3.10. Note: The designations employed and the presentation of the material on this map do not imply the expression of any opinion whatsoever on the part of Research Square concerning the legal status of any country, territory, city or area or of its authorities, or concerning the delimitation of its frontiers or boundaries. This map has been provided by the authors. 


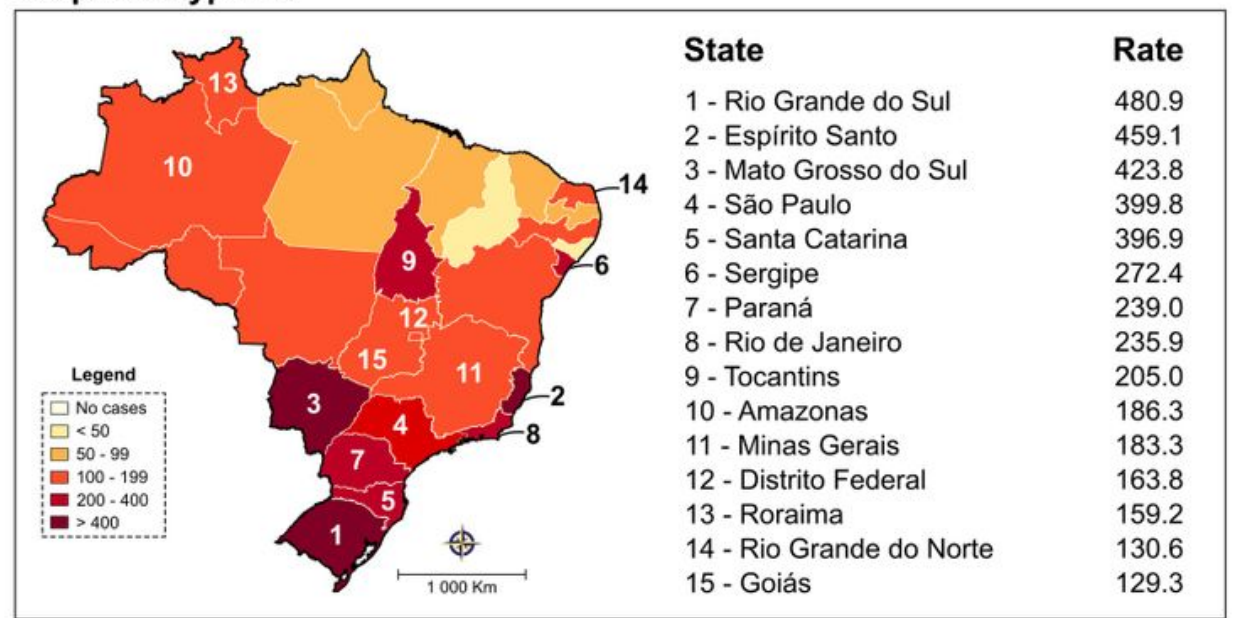

\section{Congenital syphilis}

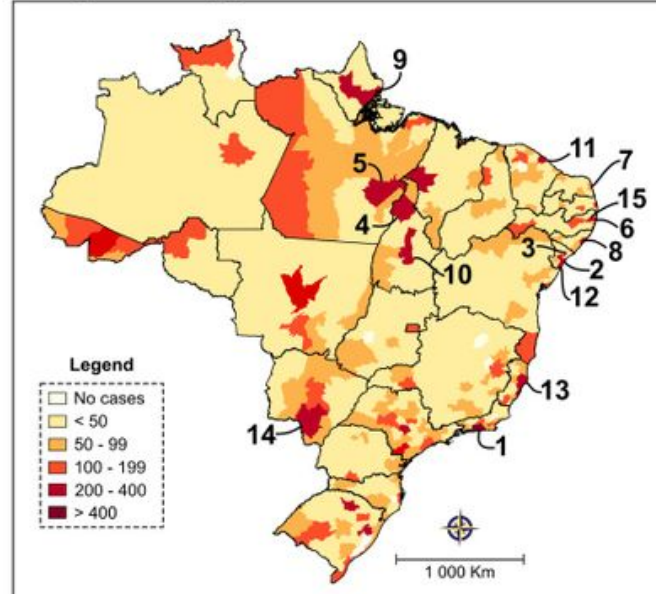

\section{Microregion}

Rate

1 - Rio de Janeiro

544.2

2 - Aracaju

384.3

3 - Cotinguiba

366.0

4 - Araguaína

359.0

5 - Marabá

337.7

6 - Recife

335.1

7 - Natal

320.7

8 - Maceió

292.5

9 - Macapá

10 - Porto Nacional

290.1

288.6

11 - Fortaleza

259.0

12 - Estância 250.5

13 - Linhares 243.4

14 - Dourados 229.7

15 - Vitória de Santo Antão $\quad 228.1$

\section{Syphilis in pregnancy}

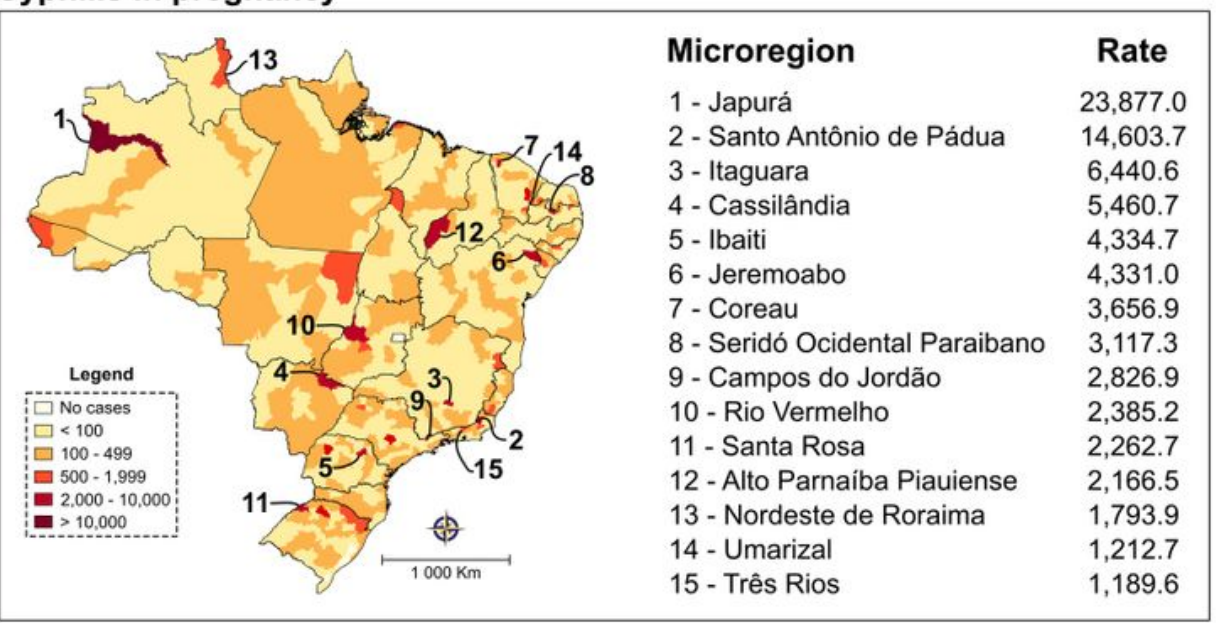

\section{Figure 8}

Spatial distribution of AS (2010 to 2018), CS and SiP (2001 to 2017) in microregions. The top 15 states or microregions with the highest cumulative rates per 100,000 inhabitants. Digital maps in the public domain were obtained from IBGE cartographic database in shapefile format (.shp) and reformatted and analyzed using QGIS version 3.10. Note: The designations employed and the presentation of the material on this map do not imply the expression of any opinion whatsoever on the part of Research Square 
concerning the legal status of any country, territory, city or area or of its authorities, or concerning the delimitation of its frontiers or boundaries. This map has been provided by the authors.

\section{Acquired syphilis}

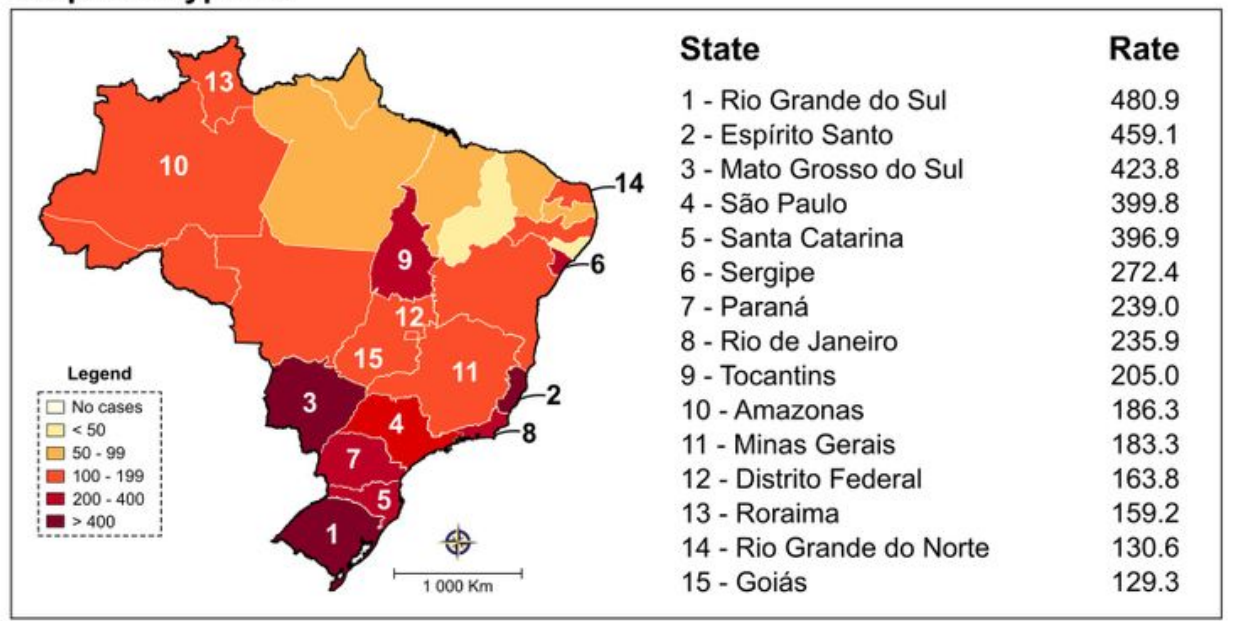

\section{Congenital syphilis}

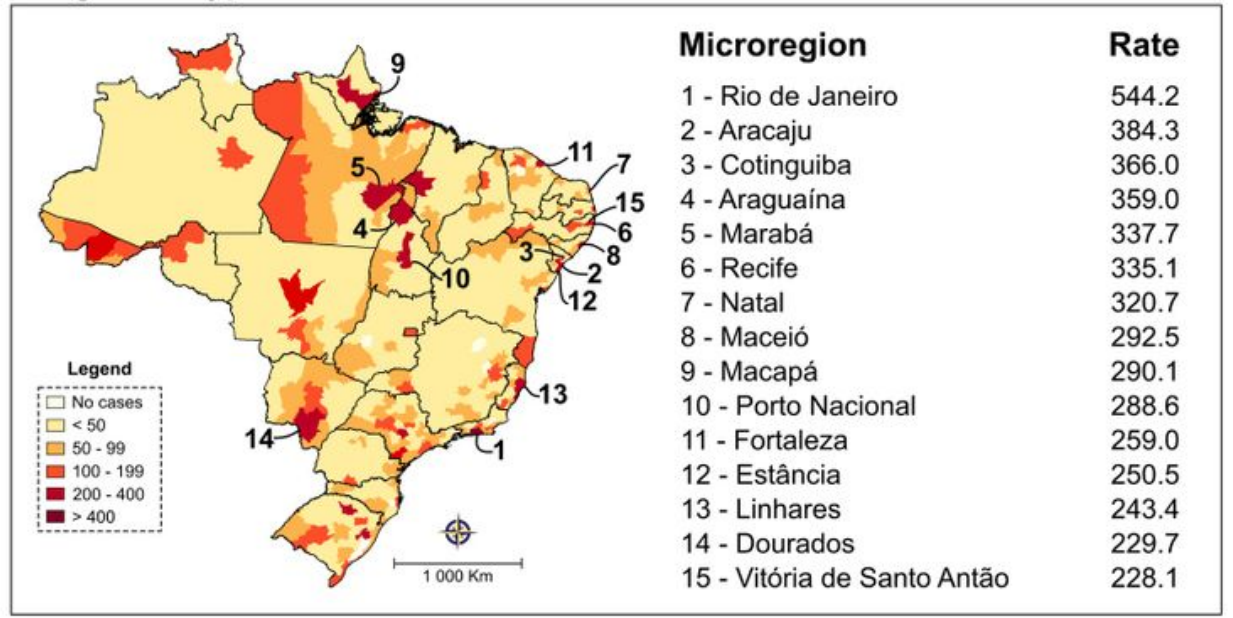

\section{Syphilis in pregnancy}

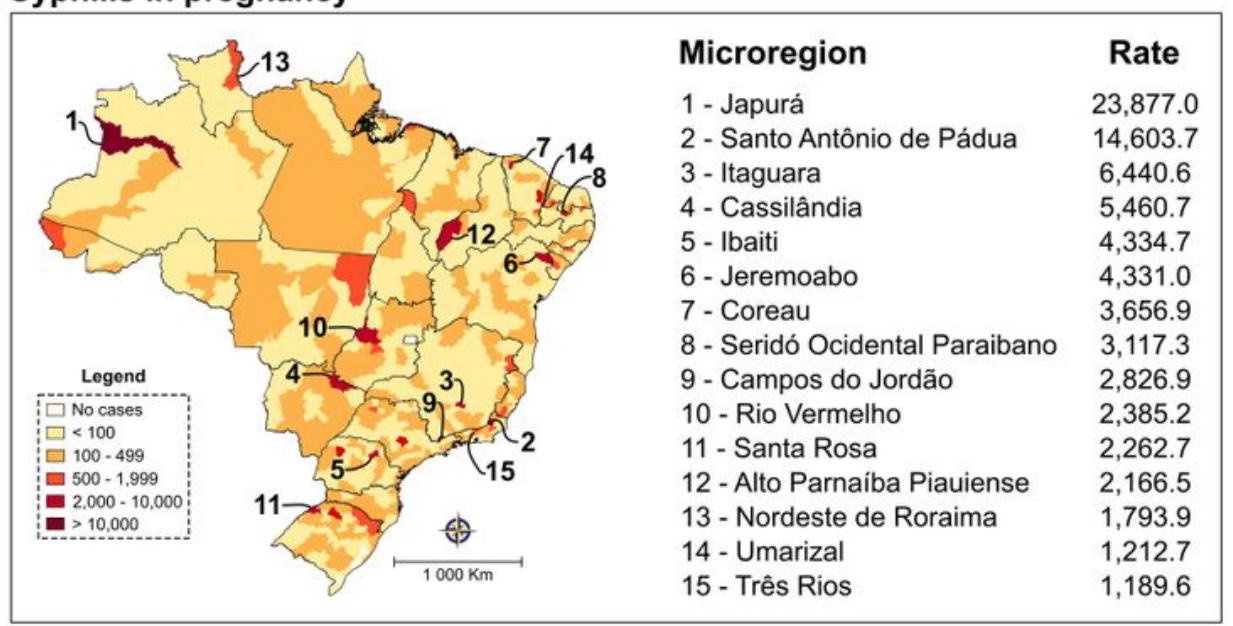

\section{Figure 8}

Spatial distribution of AS (2010 to 2018), CS and SiP (2001 to 2017) in microregions. The top 15 states or microregions with the highest cumulative rates per 100,000 inhabitants. Digital maps in the public domain were obtained from IBGE cartographic database in shapefile format (.shp) and reformatted and 
analyzed using QGIS version 3.10. Note: The designations employed and the presentation of the material on this map do not imply the expression of any opinion whatsoever on the part of Research Square concerning the legal status of any country, territory, city or area or of its authorities, or concerning the delimitation of its frontiers or boundaries. This map has been provided by the authors.

\section{Supplementary Files}

This is a list of supplementary files associated with this preprint. Click to download.

- Additionalfile1.docx

- Additionalfile1.docx

- Additionalfile2.xlsx

- Additionalfile2.xlsx

- Additionalfile3.xlsx

- Additionalfile3.xIsx

- Additionalfile4.xlsx

- Additionalfile4.xIsx

- Additionalfile5.xlsx

- Additionalfile5.xlsx

- Additionalfile6.xlsx

- Additionalfile6.xIsx

- Additionalfile7.xlsx

- Additionalfile7.xIsx 